\title{
Improved Pharmacodynamic Potential of Rosuvastatin by Self-Nanoemulsifying Drug Delivery System: An in vitro and in vivo Evaluation
}

This article was published in the following Dove Press journal: International Journal of Nanomedicine

\author{
Ravinder Verma $\mathbb{D D}^{\prime}$ \\ Ajeet Kaushik (iD ${ }^{2}$ \\ Rafa Almeer ${ }^{3}$ \\ Md Habibur Rahman (iD ${ }^{4}$ \\ Mohamed M Abdel- \\ Daim iD ${ }^{3,5}$ \\ Deepak Kaushik (iD) \\ 'Department of Pharmaceutical Sciences, \\ M.D. University, Rohtak, Haryana, \\ 12400 I, India; ${ }^{2}$ NanoBioTech Laboratory, \\ Health Systems Engineering, Department \\ of Natural Sciences, Division of Sciences, \\ Arts, \& Mathematics, Florida Polytechnic \\ University, Lakeland, FL, 33805-853I, \\ USA; ${ }^{3}$ Department of Zoology, College \\ of Science, King Saud University, Riyadh, \\ I I45I, Saudi Arabia; ${ }^{4}$ Department of \\ Pharmacy, Southeast University, Banani, \\ Dhaka, I213, Bangladesh; ${ }^{5}$ Pharmacology \\ Department, Faculty of Veterinary \\ Medicine, Suez Canal University, Ismailia, \\ 41522, Egypt
}

Correspondence: Deepak Kaushik Department of Pharmaceutical Sciences, Maharshi Dayanand University, Rohtak, Haryana, I2400I, India

Tel $+9 \mid-931580962$

Email deepkaushik1977@gmail.com

Mohamed M Abdel-Daim Department of Zoology, College of Science, King Saud University, P.O. Box 2455, Riyadh, II45I, Saudi Arabia Email abdeldaim.m@vet.suez.edu.eg
Purpose: The purpose of this proposed research was to investigate a nano-formulation developed using self-nanoemulsifying drug delivery system (SNEDDS) to improve the pharmacodynamic potential of rosuvastatin by assisting its transportation through lymphatic circulation.

Methods: The utilized lipids, surfactants, and co-surfactants for SNEDDS were selected on the basis of solubility studies. The SNEDDS formulation was optimized by implementing a D-optimal mixture design, wherein the effect of concentration of Capmul MCM EP $\left(\mathrm{X}_{1}\right)$, Tween $20\left(\mathrm{X}_{2}\right)$ and Transcutol $\mathrm{P}\left(\mathrm{X}_{3}\right)$ as independent variables was studied on droplet size $\left(\mathrm{Y}_{1}\right)$, \% cumulative drug release $\left(\mathrm{Y}_{2}\right)$ and self-emulsification time $\left(\mathrm{Y}_{3}\right)$ as dependent variables. The optimized formulation was evaluated via in vitro parameters and in vivo pharmacodynamic potential in Wistar rats.

Results: The D-optimal mixture design and subsequent ANOVA application resulted in the assortment of the optimized SNEDDS formulation that exhibited a droplet size of nano range $(14.91 \mathrm{~nm})$, in vitro drug release of $>90 \%$ within 30 minutes, and self-emulsification time of 16 seconds. The in vivo pharmacodynamic study carried out using Wistar rats confirmed the better antihyperlipidemic potential of developed formulation in normalizing the lipidic level of serum in contrast to pure drug and marketed tablets.

Conclusion: This research reports the application of D-optimal mixture design for successful and systematic development of rosuvastatin-loaded SNEDDS with distinctly enhanced in vitro and in vivo performance in comparison to marketed formulation. Eventually, improved anti-hyperlipidemic efficacy was envisaged which might be attributed to increased drug solubility and absorption. Overall, this study shows the utility of SNEDDS for improving the dissolution rate and bioavailability of poor aqueous-soluble drugs. The present SNEDDS formulation could be a promising approach and alternative to conventional dosage form.

Keywords: SNEDDS, rosuvastatin, in vitro lipolysis, nanotechnology, D-optimal mixture design, pharmacodynamic study

\section{Introduction}

Hyperlipidemia is described as an increase in the concentration of lipids in the bloodstream, that is why it is also known as hypercholesterolemia or hypertriglyceridemia. Atherosclerosis and cardiovascular disease are its prime risks, which resulted in approximately 800,000 deaths in 2005 as the primary reason for death in the United States with yet increasing number of incidents. Rosuvastatin calcium (BCS II class drug) is a first-line therapy drug to treat hyperlipidemia, with better 
results than other statins. ${ }^{1}$ It is also known as a "superstatin" due to its most significant potential for antilipidemic conditions. Its low aqueous solubility is responsible for its slow dissolution rate and low bioavailability (20\%). Thus, improvement in its dissolution can lead to its improved bioavailability. ${ }^{2}$

Nanotechnology has presented a novel perception to human knowledge and has led to innovation in the field of biological sciences including, diagnostics, food, drug delivery, biomaterials for implants or prosthesis, and the production of biomimetics appropriate for applications in the field of medicine. ${ }^{3}$ Nanotechnology is gaining significance because it concerns small size and targeted properties. Nanoscale formulations have a size range of 100-10000 times smaller than that of human cells. As a consequence of their small size and bigger surface area, they can easily interact with enzymes and receptors on the surface of the cell and inside the cell. After being administered to various regions of the body, they have the capability to "spot" disease at extremely low level and deliver medicament. ${ }^{4}$ Nanotechnology is the most promising technology over the last two decades and various efforts are ongoing to extend its applications in various streams of pharmaceutical sciences. Many nanoscale carriers have been recently explored for improving the therapeutic performance of drugs. ${ }^{5}$

Nanomedicine is the main and exhaustive field of research in nanotechnology and applicable widely for the diagnosis, prevention, and treatment of diseases. ${ }^{6}$ Nano drug designing has been investigated at broad level and these are the nano-formulations that are considered under novel advanced technology in Pharmaceutical Science. It has the potential to alter drug release profile, solubility, and bioavailability. Their main advantages are ability to target a specific site, reduction of toxicity, improvement of bioavailability, improving stability and reduction of dosing frequency by development of controlled release formulation. Therefore, it can be summed up that nanotechnology plays a vital role in the improvement of safety, patient compliance, efficacy and drug shelf life. ${ }^{7}$

Despite various novel innovations for the delivery of dynamic pharmacotherapeutic mixes, drug formulation through the oral route is viewed as the most common for patients of all ages. ${ }^{8}$ The high-dose requirements of some drugs have intensified the need to design nano-enabled drug delivery systems (DDSs), which have many benefits over conventional DDSs. ${ }^{9}$ Recently, attention has been focused toward the nanoscale manipulation of DDSs offering inimitable features for navigation of drugvehicle and controlled drug release, which is often not achievable in conventional- (eg, free-form) and microscale-drug carriers. ${ }^{10}$ The current strategy of developing bio-polymeric SNEDDS has pronounced conviction of incorporating inherent features of no toxicity, biodegradability, biocompatibility, and high sensitivity. Recently, SNEDDS have been labeled as personalized health-care due to advancements in DDS for improved efficacy and least side-effects.

Self-nanoemulsifying drug delivery systems (SNEDDS) is an important approach that merges the advantages of lipid-based drug delivery system and nanotechnology. SNEDDS is a novel methodology in the delivery of drugs and tackles inadequacy associated with the delivery of BCS II class drugs. ${ }^{11,12}$ SNEDDS are depicted as transparent formulations comprised of oil, surfactant, and cosurfactant that creates droplets of ultrafine oil in water $(\mathrm{o} / \mathrm{w})$ nanoemulsion with a mean droplet range of $<100 \mathrm{~nm}{ }^{13}$ They facilitate in having of greater solubilization limit, prompting the expansion of drug in oily phase. ${ }^{14,15}$ The ingredients present in these will encourage bioavailability (BA) of the drug not only by enhancing their permeability and solubility, but also by dodging their metabolism via liver and repressing P-glycoprotein efflux, alongside the capacity to encourage lymphatic assimilation of the drug. A few reports based on these formulations have proven possible enhancement of BA of different drugs. ${ }^{16-20}$

Nano-emulsions are emerging as very useful to improve performance of various biomedical systems based on drug delivery, food, cosmetics and pharmaceuticals because of their small size and useful properties such as high surface area per unit volume, robust dilution stability, optical transparency and tunable rheology. ${ }^{21}$ Due to small droplet size, nano-emulsions possess stability against sedimentation or creaming with Ostwald ripening that is the main mechanism of nano-emulsion breakdown. This is the main reason for their thermo-kinetic stability. ${ }^{22,23}$

The present study was planned to investigate the in vitro and in vivo evaluation of rosuvastatin-loaded SNEDDS formulation. In this study, SNEDDS were developed with Capmul MCM EP (oil), Tween 20 (surfactant), Transcutol (co-surfactant) and the formulation was optimized by implementation of D-optimal mixture design. The optimized SNEDDS formulation was characterized for globule size, zeta potential, DSC, FT-IR, and stability studies. Further, food-effect, in vitro and in vivo 
investigations were carried out. Transmission electron microscopy (TEM) and laser particle size analyzer were utilized to estimate shape and size of the resultant nanoemulsion. Because of these contemplations, the principle point of the current research was the utilization of optimization strategy for methodical product development that aids in accomplishing predictable quality and vigorous execution. Optimization strategy gives product and process understanding for consistent development. Experimental design was considered a key tool that maximizes data utilizing the least experimental work. ${ }^{24}$

\section{Materials and Methodology Materials}

Pure rosuvastatin was a liberal sample from Sun Pharmaceutical Laboratories, Gurugram. Capmul MCM EP was sympathetically provided by IMCD, Delhi. Tween 20 was purchased from Croda, Transcutol P from Gattefosse, and Pancreatin from Loba Chemie. Rosufine $20 \mathrm{mg}$ tablets of batch no. C-90061 were obtained from a drug store. Other ingredients and reagents utilized in the current research were of analytical grades.

\section{Methodology}

Investigation of Rosuvastatin's Solubility in Various Ingredients

Considering the therapeutic dose strength of rosuvastatin, a higher medicament loading capacity of SNEDDS is required. When deciding on and plotting achievable emulsification milieu, it was important to determine solubility of rosuvastatin in various oils or surfactants. ${ }^{25}$

The super saturation solubility of rosuvastatin was examined in different ingredients for the selection of right ingredient which revealed high solubilizing potential and maximum drug loading for rosuvastatin. An excess amount of rosuvastatin was blended with every excipient ( $2 \mathrm{~g}$ ) in a screw-topped glass vial. Vortex blender (Genius, India) was utilized for the best possible mixing of rosuvastatin with ingredients. $^{26}$

For the blending of mixture, thermostatic control shaker (Calton, Germany) was utilized for $72 \mathrm{~h}$ at $100 \mathrm{rpm}$. After the collection of samples, centrifugation (Remi, Mumbai) was carried out for 30 minutes at $5000 \mathrm{rpm}$. The supernatant was gathered and $0.45 \mu \mathrm{m}$ membrane filters were utilized for filtering of solution. The amount of rosuvastatin was investigated utilizing UV-spectrophotometer (UV 1700, Shimadzu, Japan) at $242 \mathrm{~nm}$. The examination was performed in triplicate. ${ }^{27}$ The self-emulsification limit of oil and surfactant was explored for picking their best combination. Each oil was titrated with $10 \mathrm{~mL}$ of every surfactant $(10 \% \mathrm{w} / \mathrm{w}$ aqueous solution). We noted the volume of oil when it changed over emulsion clearness into cloudy transform and selected the blend that offered the most elevated amount of oil emulsified. ${ }^{28,29}$

Smix of 1:1 was prepared with every co-surfactant in order to choose the best combination and different preparations were formulated with selected oil and Smix. $520 \mathrm{mg}$ of every preparation was mixed with purified water $(500 \mathrm{~mL})$ and we recorded the clarity of the resultant nano-emulsion. ${ }^{30}$

\section{Plotting of Ternary Phase Diagram}

This was constructed with each selected ingredient and all of them address a side of this diagram. Ternary mixes with the three different excipients were prepared, resulting in a total entirety of $1 \mathrm{~g}$. Smix was mixed in four ratios $1: 1$, $2: 1,1: 2$ and $3: 1$ in order to choose the ratio with maximal region for nano-emulsion formation. Oil and explicit Smix ratios were mixed totally in 9 differing weight extents from 1:9 to $9: 1$ in different glass vials. ${ }^{31,32}$ The objective was that most outrageous extents were planned for the assessment to plot phase exactness restrictions made in this diagram. ${ }^{25}$ Its blueprints were made using "water dilution" technique. The development of nano-emulsion was observed as a clear/transparent solution that confirms the production of SNEDDS with low consistency of $\mathrm{o} / \mathrm{w}$ nano-emulsion. The proportion of each ingredient (oil and Smix) was documented and presented in it. It was designed with Chemix software (Chemix Version 4.5). ${ }^{33,34}$

\section{Optimization of SNEDDS}

In recent times, various statistical designs have been used to even more expertly enhance strategy using less experimentation and estimate the significance of independent variables. There are various tools for statistical optimization. Among them, D-optimal mixture design is one of the most standard surface methodologies for their optimization since it confines the distinction identified with assessment of coefficient in model and conveys the perfect subset by considering measures for enhancing statistics grid determinant. In this design, complete arrangement of formulation is considered as 100\%, while other designs do not consider it. $^{35,36}$

The concentrations of Capmul MCM EP $\left(\mathrm{X}_{1}\right)$, Tween $20\left(\mathrm{X}_{2}\right)$ and Transcutol $\mathrm{P}\left(\mathrm{X}_{3}\right)$ were considered as 
independent variables for the formulation of SNEDDS with the least droplet size $\left(\mathrm{Y}_{1}\right)$, maximum \%CDR $\left(\mathrm{Y}_{2}\right)$ and self-emulsification time $\left(\mathrm{Y}_{3}\right)$ as dependent variables. The design of experiment (DoE) which aids in analyzing and recording the dependent variables $(\mathrm{Y})$ as outcomes (Design Expert ${ }^{\circledR}$ Software 10) was employed for harmonization of regression equation for calculation of the dependent variables. ${ }^{37}$ Three equations of regression and desirability index helped in the selection of the optimized SNEDDS formulation.

\section{Evaluation of Globule Size}

For this analysis, optimized SNEDDS formulation was diluted $(1: 100 \mathrm{w} / \mathrm{v})$ with purified water and mixed for 1 minute prior to investigating this parameter. Zetasizer ZS of nano series; Malvern Instruments, Malvern, UK was utilized for the measurement of these parameters that is based on photon correlation spectroscopy. ${ }^{38}$

\section{Dissolution Study}

In this, $900 \mathrm{~mL}$ of $\mathrm{pH} 6.6 \pm 0.05$ sodium citrate buffer media of $0.05 \mathrm{M}$ at $37^{\circ} \mathrm{C} \pm 0.5^{\circ} \mathrm{C}$ was used in paddle type dissolution apparatus (Distek, USA) at $50 \mathrm{rpm}$. The capsules filled with SNEDDS (equivalent to $20 \mathrm{mg}$ of rosuvastatin in capsule) were added into the cradle media ensuing to starting the revolution of paddle. Aliquots $(5 \mathrm{~mL})$ were collected after 30 minutes and examined via UV-spectrophotometer (UV 1700, Shimadzu, Japan) at $\lambda \max 242 \mathrm{~nm}$. This analysis was performed in triplicate. ${ }^{39}$

\section{Self-Emulsification Time}

Based on the reported method, this study was done on every developed formulation. In brief, $1 \mathrm{~g}$ formulation of SNEDDS was incorporated in $500 \mathrm{~mL}$ of purified water and a magnetic stirrer (Remi, Mumbai) was used for agitation of $100 \mathrm{rpm}$. Time taken for development of nanoemulsion and dispersibility was recorded. ${ }^{40}$

\section{Characterization}

In view of enhancement results, optimized SNEDDS was picked to complete characterization and more evaluation parameters.

\section{Differential Scanning Calorimetry}

The thermochemical features of pure rosuvastatin, physical mixture (rosuvastatin + Capmul MCM EP + Tween 20 + Transcutol P) and rosuvastatin-loaded SNEDDS were characterized by differential scanning calorimetry (DSC) using DSC Q10 (TA Instruments, USA) at the heating rate of $10^{\circ} \mathrm{C} / \mathrm{min}$. For sample preparation, $5 \mathrm{mg}$ of sample was kept in an aluminum pan and enclosed with an aluminum lid. The results of the analysis were evaluated in the range of $10-300^{\circ} \mathrm{C}$. The peak melting temperature for each endothermic curve in the overlay thermogram was assessed automatically using TA Universal Analysis software. $^{41}$

\section{Fourier Transform Infrared Spectroscopy (FT-IR)}

FT-IR investigations were carried out to assess whether any possible interaction was occurring among drug, oil, surfactant and co-surfactant. The samples were analyzed by Fourier Transform Infrared spectroscopy (Bruker Alpha, USA). A suitable quantity of pure rosuvastatin, physical mixture (rosuvastatin + Capmul MCM EP + Tween $20+$ Transcutol P) and rosuvastatin-loaded SNEDDS was compressed for 5 min at 5 bars on a $\mathrm{KBr}$ press and the samples were scanned on the wavenumber range of $400-4400 \mathrm{~cm}^{-1} .42$

\section{Test for \% Transmittance}

It was estimated for the detection of in vivo effect on the solubilization of the capacity of drug subsequent to dilution in the lumen of the gut. During their development for oral route, there are possibilities for a decline in solubilization capacity that will result in precipitation of the drug. $1 \mathrm{~g}$ of formulation was diluted with purified water $(100 \mathrm{~mL})$ and estimated at $242 \mathrm{~nm}$ utilizing UV spectrophotometer and performed in triplicate utilizing purified water as a blank. ${ }^{43}$

\section{Robustness Dilution Test}

In this, the formulation was explored to the different media such as $\mathrm{pH} 1.2$ of $0.1 \mathrm{~N} \mathrm{HCl}, \mathrm{pH} 4.5$ of Acetate buffer and $\mathrm{pH}$ 6.8 of phosphate buffer after 100 times dilution. After putting these formulations for 24 hours, they were evaluated for phase separation/drug precipitation by visual observation. ${ }^{44}$

\section{Viscosity Estimation}

This was measured by using Hyrdromotion viscometer (Brookfield Engineering, USA). This test was conducted to confirm the type of developed nano-emulsion, whether it was o/w type or w/o type nano-emulsion. The low viscosity of developed nano-emulsion confirms its $\mathrm{o} / \mathrm{w}$ type of nano-emulsion and vice-versa. ${ }^{45}$

\section{Estimation of Cloud Point}

It was measured after 100-times dilution of SNEDDS (1 g) 
with purified water and set aside for a regular rise in water bath (Julabo, Germany) temperature at $10^{\circ} \mathrm{C} /$ minute increment. ${ }^{46}$

\section{Analysis of Drug Content}

The optimized formulation was diluted with methanol (10times) and centrifugation was conducted for 30 minutes at $10,000 \mathrm{rpm}$. At that point, supernatant was diluted with methanol (2.5 times) and examined for drug content via UV spectrophotometer at $242 \mathrm{~nm}$, performed in triplicate. ${ }^{47-49}$

Investigation of Droplet Size, Polydispersity Index (PDI) and Zeta Potential

Small size globule results in better emulsifying ability of the formulation. For this analysis, optimized SNEDDS formulation was diluted $(1: 100 \mathrm{w} / \mathrm{v})$ with water and mixed for 1 minute prior to investigating these parameters. Zetasizer $\mathrm{ZS}$ nano series was utilized for the measurement of these parameters that is based on photon correlation spectroscopy. It was performed in triplicate and shown as mean. ${ }^{50,51}$

\section{Drug Entrapment Efficiency}

Entrapment efficiency (EE) of rosuvastatin SNEDDS was examined as per the procedure established by Ke et al. In brief, the content of free rosuvastatin was separated from SNEDDS by the ultrafiltration method (3500 Da) with centrifugation at $3000 \mathrm{~g}$ for 5 minutes followed by qualification using UV spectrophotometer at $242 \mathrm{~nm}$. The EE was calculated as follows:

$$
E E=\frac{\mathrm{Wt}-\mathrm{Wf}}{\mathrm{Wt}} \mathrm{X} 100
$$

where $W_{\mathrm{t}}$ is the total amount of rosuvastatin in nanoemulsion and Wf is the amount of free rosuvastatin. ${ }^{52}$

\section{Surface Morphology Determined via Transmission Electron Microscopy (TEM)}

The morphology of the formed nano-emulsion (1:100 dilutions) was determined using TEM (JEM2100+ microscope JEOL, Japan). The nano-emulsion was negatively stained with $2 \%$ phosphotungstic acid, kept for 3 minutes at room temperature and allowed to dry before observation under the electron microscope. ${ }^{49}$

\section{Dissolution (Multi-Media) Testing}

SNEDDS (filled in size "00" capsule) were placed in dissolution media of $\mathrm{pH} \mathrm{1.2,} 4.5$ acetate and 6.6 citrate buffers at $37^{\circ} \mathrm{C} \pm 0.5^{\circ} \mathrm{C}$ in paddle-type dissolution apparatus (Distek, USA). Samples $(5 \mathrm{~mL})$ were collected at a fixed interval of time; the equivalent amount of new fresh media was added after completion of every sampling. The samples were filtered with $0.45 \mu \mathrm{m}$ nylon Millipore membrane filters. The drug discharge rate was estimated utilizing UV spectrophotometer at $242 \mathrm{~nm}$ after proper dilution and performed in triplicate. ${ }^{53-55}$

\section{Comparative Investigation of SNEDDS with Marketed} Tablets and Pure Drug in Terms of Dissolution Profile

This investigation was carried out with pure rosuvastatin, SNEDDS and marketed formulation (Rosufine 20 with batch no. C-90061) in "USP Type-II dissolution assembly (Distek, USA) with $900 \mathrm{~mL}$ of $0.05 \mathrm{M}$ sodium citrate dissolution media of $\mathrm{pH} 6.6 \pm 0.05$ at $50 \mathrm{rpm}$ as specified by USFDA dissolution database". A cellulose membrane dialysis sac (MWCO 12,000 g/mole; Sigma-Aldrich) was filled with equivalent volume of rosuvastatin-loaded optimized SNEDDS, marketed tablets and pure drug (rosuvastatin equivalent to $20 \mathrm{mg}$ ). These formulations were placed at the bottom of the vessels using a suitable sinker. On the basis of already established time intervals, $5 \mathrm{~mL}$ aliquots were collected and examined for drug release utilizing UV spectrophotometer. ${ }^{39}$

\section{Dynamic in vitro Lipolysis Study for Investigation of Food} Impact

The literature database confirmed that SNEDDS avoids food impact on the formulation by using drug release. For demonstrating this hypothesis, the dissolution of optimized SNEDDS was carried out in modified Fasted/Fed state simulated intestinal fluid V-2 (Fa/FeSSIF V-2) media to simulate an in vivo environment.

It is fundamental for superlative experimental relevance to perform in vitro examination of the drug to mirror in vivo condition as eagerly as could rationally be predicted. This examination is essential for two explicit justifications. Initially, measurement of level and rate of lipolysis that helps to investigate solubility and dispersion features of formulation. The second one is the analysis of post lipolysis to predict solubilized or precipitated form of the drug after completing the reaction. This model can reliably predict the limit of these preparations to improve oral retention of drugs with low solubility in the aqueous phase.

In this study, dynamic in vitro lipolysis examination was an interpretation of methodology as of late described by Mohsin. ${ }^{56}$ Each $550 \mathrm{mg}$ of SNEDDS was supplemented with both media $(36 \mathrm{~mL})$, the formula of which is shown in Table $1^{57,58}$ Compositions of $\mathrm{Ca}^{2+}$, bile salt (BS), 
phospholipids (PLs), and sodium chloride $(\mathrm{NaCl})$ were linked to mimic representative concentration existing in $\mathrm{Fa} / \mathrm{FeSSIF} \mathrm{V}-2$. Amid the early period of dispersion, $\mathrm{pH}$ $6.5 / 5.8 \pm 0.05$ was kept constant with $\mathrm{NaOH}$ or $\mathrm{HCl}$.

The blending process was done by mixing on the magnetic stirrer with hot plate at $37^{\circ} \mathrm{C}$ to emulsify SNEDDS before adding the pancreatic extract solution having pancreatic lipase enzyme. Addition of $4 \mathrm{~mL}$ pancreatic concentrate [prepared by suspending $1 \mathrm{~g}$ of pancreatin powder in $5 \mathrm{~mL}$ of digestion buffer and vortex mixing for 15 minutes. ${ }^{59}$ For the collection of the supernatant of $\mathrm{pH} 6.5 /$ 5.8 having pancreatic lipase activity of $800 \mathrm{TBU} / \mathrm{mL}$, ultracentrifugation (Remi, Mumbai) was conducted to digestion buffer that starts lipolysis, which was continued for the next 30 minutes. During lipolysis, the creation of unsaturated fats (FAs) brings about a rise in $\mathrm{pH}$ of media, $\mathrm{NaOH}$ solution of $0.2 \mathrm{M}$ was used for achieving constant $\mathrm{pH}$ of $6.8 / 5.8$. The progress of drug discharge was observed by UV examination at $242 \mathrm{~nm} .{ }^{60,61}$ The current technique was viewed as robust and assessed results were found to be reproducible by following this procedure.

\section{Stability Study}

50 capsules filled with SNEDDS (equivalent to $20.0 \mathrm{mg}$ of rosuvastatin in each capsule) were kept in 60cc HDPE bottle. These bottles were put in an accelerated condition $\left(40 \pm 2^{\circ} \mathrm{C} / 75 \pm 5 \% \mathrm{RH}\right)$ in the stability chamber (Thermolab, India) for six months subsequent to the sealing of these bottles. At periodic times, test samples were expelled and assessed for physical appearance, \% drug discharge, and time of disintegration. ${ }^{62,63}$

\section{Pharmacodynamic Investigation}

It has been reported that rosuvastatin has dose-dependent

Table I Composition of Biorelevant Media Used During in vitro Lipolysis

\begin{tabular}{|l|l|l|}
\hline Chemicals & FaSSIF V-2 & FeSSIF V-2 \\
\hline Sodium taurocholate $(\mathrm{mM})$ & 3 & 10 \\
Glyceryl monooleate $(\mathrm{mM})$ & - & 2 \\
Sodium oleate $(\mathrm{mM})$ & - & 5 \\
Lecithin (mM) & 0.2 & 0.8 \\
Maleic acid (mM) & 19.12 & 55.02 \\
$\mathrm{NaCl}(\mathrm{mM})$ & 68.62 & 125.5 \\
$\mathrm{NaOH}(\mathrm{mM})$ & 34.8 & 81.65 \\
$\mathrm{pH}$ & 6.5 & 5.8 \\
\hline
\end{tabular}

Abbreviations: FaSSIF V-2, fasted state simulated intestinal fluid $\mathrm{V}-2$; FeSSIF V-2, fed state simulated intestinal fluid $\mathrm{V}-2$. pharmacodynamic impact and that is the reason for the execution of this in vivo investigation with a marketed tablet.

The ethical approval for this investigation of rosuvastatin SNEDDS was granted by Institutional Animal Ethical Committee (IAEC), Maharshi Dayanand University, India (Reg. no. 1767/RE/S/14/CPCSEA, vide reference no. 153165 dated 14/12/2018). Male Wistar rats having weight 150-200 g were purchased from Lala Lajpat Rai University of Veterinary and Animal Sciences, Hisar. Animals were maintained as per the guidelines of Committee for the Purpose of Control and Supervision of Experiments on Animals (CPSEA), India.

All rats were set aside in plastic cage; six rats were accommodated in a single cage.

All rats were divided into 5 groups (total 30 rats; $n=6$ rat for each group), ie, control treatment group (CTG), placebo treatment group (PTG), reference treatment group (RTG), test (TTG) and marketed treatment group (MTG).

The impact of rosuvastatin SNEDDS formulation (TTG) on the lipidic profile was investigated by contrasting with rosuvastatin pure drug (RTG) and SNEDDS lacking rosuvastatin (PTG). Marketed, test, reference and placebo formulations were diluted with acacia solution $(2.0 \%)$. Every group got a high-fat diet (mixture of dalda and coconut oil [3:2]) at a dose of $10 \mathrm{~mL}$ per $\mathrm{kg}$ per day body weight daily for a period of 4 weeks. TTG, RTG, MTG, and PTG were administered for 4 weeks with test, reference, marketed and placebo formulation, respectively. Test and reference formulations were administered through oral route at dose of $2 \mathrm{mg}$ per $\mathrm{kg}$ per day of rosuvastatin. The blood samples were collected by a retro-orbital puncture method at a predetermined time interval, namely, before treatment and after 28 days in polo plain clot activator glass tubes. ${ }^{64}$ Ultracentrifugation was carried out for 10 min at $3000 \mathrm{rpm}$ (Remi) for separation of serum and samples were analyzed for biochemical test such as $\mathrm{CH}$, HDL and TGs level with in vitro diagnostic kits (Erba ${ }^{\circledR}$ Mannheim) and analyzer (Erba ${ }^{\circledR}$ with software Chem-5 Plus V2). ${ }^{65}$

For the determination of total cholesterol $(\mathrm{CH})$, modified Roeschlau's method was used. The method of Wako and the modification by McGowan and Fossati were used for the determination of triglycerides (TG). The method of Burstein was used for the determination of highdensity lipoprotein (HDL). ${ }^{64}$ Total $\mathrm{CH}$, TG VLDL and 
HDL (0 days and after 28 days) for each treatment group, ie, CTGs, PTGs, TTGs and RTGs were obtained.

The differences in the mean of various groups were analyzed by the implementation of one-way ANOVA with the Dunnet's test in Graph Pad version 5.0 software. A p-value less than 0.05 is acceptable for statistical significance.

\section{Result and Discussion Investigation of Drug Solubility}

For assurance of stability of SNEDDS, solubility of the drug in excipients performs an important role since numerous formulations experience precipitation prior to encountering in situ solubilization. High drug solubilization is extremely important for expanding drug loading. ${ }^{66}$ Moreover, for development of rosuvastatin SNEDDS, its recommended sum ought to be soluble in its chosen ingredients with the least quantity of blend. ${ }^{67}$ The solubility of rosuvastatin in different excipients is demonstrated in Figure 1.

Self-emulsification relies upon the choice of an appropriate blend of excipients. This investigation demonstrated that Tween 20 with the highest amount of Capmul MCM EP had been emulsified, as demonstrated in Figure 2. That is the reason why Tween 20 and Capmul MCM EP combination was selected.

Transcutol $\mathrm{P}$ indicated larger nano-emulsion area in contrast with Labraso, 1 as shown in Table 2. That is why it was chosen as a co-surfactant.

The surfactant makes a coat around oil globules and decreases surface tension among the oily and aqueous phase. Further, their optimum quantity results in the improvement of the instant self-emulsification time. The rise in cosurfactant amount lessens the zone for development of emulsion, however, it has a negligible effect on decline in interfacial tension. ${ }^{68}$ A higher HLB value is important for making $\mathrm{o} / \mathrm{w}$ type emulsion. These are utilized in rosuvastatin SNEDDS mostly to limit the surfactant quantity in the preparation. ${ }^{69}$ Transcutol $\mathrm{P}$ was mixed in preparation to expand the solubilization capacity of hydrophobic drugs.

\section{Ternary Phase Diagram}

It was plotted to label self-nanoemulsifying area and select suitable concentrations of excipients for these formulations. This diagram plays a critical role in studying the phase behavior of developed nano-emulsions. ${ }^{70,71}$ It contains oil and Smix, where every vertex corresponds to $100 \%$ of those particular excipients. In Figure 3, the concealed zone introduced a transparent and lower viscosity nano-emulsion region in it. $^{72}$

It showed that a clear and transparent system is created when oil content is less than $20 \%$ (Figure S1). While biphasic systems are formed at higher concentration of oil and surfactants for development of clear nanoemulsion. However, rise in Tween 20 ratio in Smix (2:1) resulted in increase in nano-emulsion region. But, rise in concentration of Transcutol P (1:2 and 1:3) resulted in decline in nano-emulsion region. This may be due to creation of a layer around the oil globules by the Tween 20 that reduces the interfacial tension up to mark. But, Transcutol $\mathrm{P}$ had little impact on the interfacial tension.

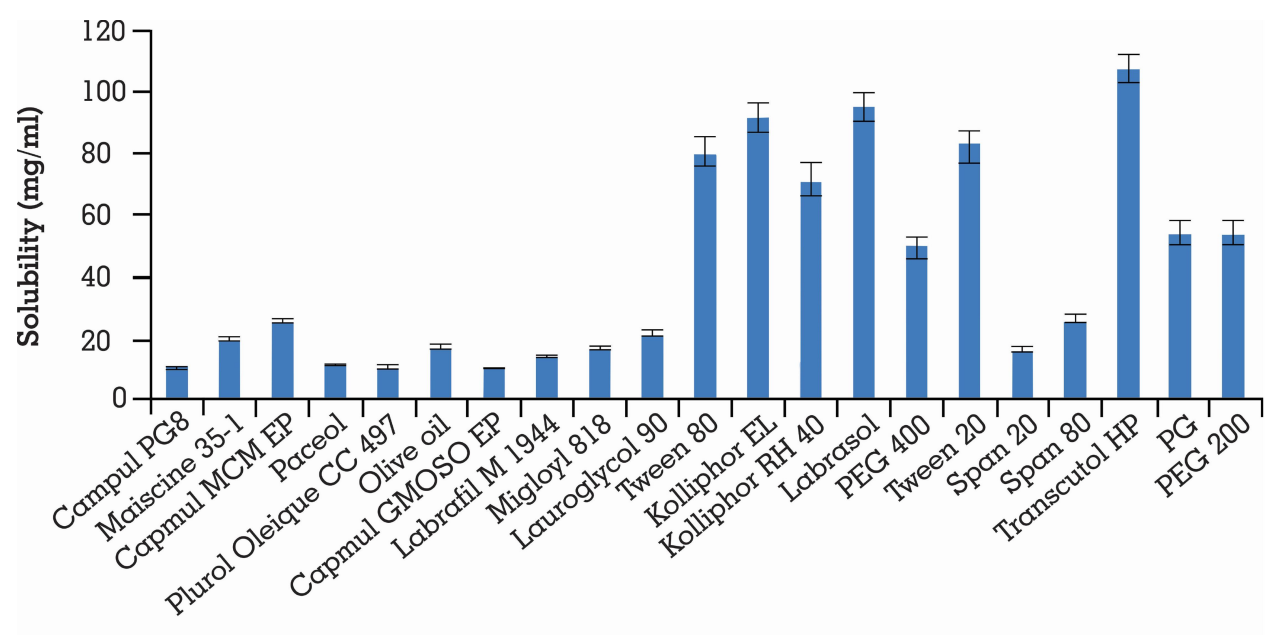

The solubility of Rosuvastatin in different oils and surfactants $(n=3)$

Figure I Solubility of rosuvastatin in different oils and surfactants. Each value shows the mean $\pm \operatorname{SD}(n=3)$. 


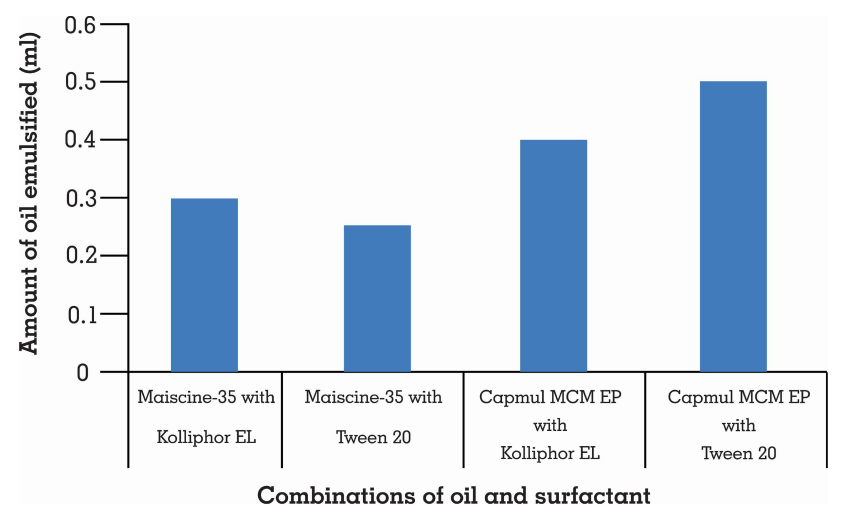

Figure 2 Self-emulsification of different oils with selected surfactants $(n=3)$.

So, rise in Transcutol P concentration will not significantly reduce the interfacial tension and maintain the thermodynamic stability of the developed systems after the dilution.

\section{D-Optimal Mixture Design for Optimization}

The effect of rosuvastatin SNEDDS factors $\left(\mathrm{X}_{1}-\mathrm{X}_{3}\right)$ on globule size, \%CDR and self-emulsification time was investigated utilizing the experimental design software. An optimized formula with the minimum globule size, maximum $\% \mathrm{CDR}$ and minimum self-emulsification time was utilized. A mixture design was utilized for optimization of rosuvastatin SNEDDS with Design Expert ${ }^{\circledR}$ software. As exhibited in Table 3, 14 trial experiments were suggested with 2 center points. $\mathrm{Y}_{1}$ varied from 14.69-$132.2 \mathrm{~nm}, \mathrm{Y}_{2}$ from $86-99.5 \%$ and $\mathrm{Y}_{3}$ from $15-40$ seconds. Equation 1, 2 and 3 explain the impact of various proportions of components on response $\mathrm{Y}_{1}, \mathrm{Y}_{2}$ and $\mathrm{Y}_{3}$.

Contour plots (2-Dimensional) are shown in Figure 4 which elucidate effect of $\mathrm{X}_{1}, \mathrm{X}_{2}$ and $\mathrm{X}_{3}$ variables on $\mathrm{Y}_{1}$,

Table 2 Nanoemulsion Region with Different Co-Surfactants

\begin{tabular}{|l|l|l|l|}
\hline$\%$ & $\%$ & Nanoemulsion Region & \\
\cline { 3 - 4 } Oil & \multirow{2}{*}{ Smix } & Smix Tween 20: & Smix Tween 20: \\
& & Transcutol P (I:I) & Labrasol ( I:I) \\
\hline 10 & 90 & Yes & Yes \\
20 & 80 & Yes & Yes \\
30 & 70 & Yes & Yes \\
40 & 60 & Yes & Yes \\
50 & 50 & Yes & No \\
60 & 40 & Yes & No \\
70 & 30 & No & No \\
80 & 20 & No & No \\
90 & 10 & No & No \\
\hline
\end{tabular}

$\mathrm{Y}_{2}$ and $\mathrm{Y}_{3}$ response. Response plots (3-Dimensional) which elucidate effect of $X_{1}, X_{2}$ and $X_{3}$ variables on $Y_{1}$, $\mathrm{Y}_{2}$ and $\mathrm{Y}_{3}$ response are shown in Figure $\mathrm{S} 2$.

It was found that globule size $\left(\mathrm{Y}_{1}\right)$ increases with an increase in oil concentration and decreases the release rate of drug $\left(\mathrm{Y}_{2}\right)$ and the time of self-emulsification $\left(\mathrm{Y}_{3}\right)$ also rises. But, the rise in surfactant's concentration resulted in a reduction of globule size and elevated release rate of drug and lessened time for selfemulsification. The raised concentration of Transcutol $P$ resulted in an increase of the globule size because of inflow of a large number of Transcutol P molecules into the oily phase resulting in expansion of interfacial film and particle size. ${ }^{61}$ From 2-D and 3-D contours, it was summarized that a higher proportion of oily phase declined globule size significantly, while other excipients raised it up to a certain value in the formulation then it starts to increase. The same results were obtained for response $\mathrm{Y}_{2}$ and $\mathrm{Y}_{3}$. The result of ANOVA is given in Table 4.

The desirability index is employed for optimization of factors in a multi-response system that is based on transformation of all responses from various scales into a scale free value. Its values lie in the range of 0 and 1 . Its value for SNEDDS was found to be 0.9832, as shown in Figure 5.

This indicates that the model is significant. Three equations of regression (Equation S1, S2 and S3) and desirability index helped in the selection of the optimized formulation. From these two parameters, Formulation 2 (F-2) was found to be the optimized batch which contained rosuvastatin $(20 \mathrm{mg})$, Capmul MCM EP (14\%), Tween 20 (50\%) and Transcutol P (36\%) having a globule size of $14.69 \mathrm{~nm}, 99.5 \%$ dissolution within 15 minutes, and self-emulsification time of 15 seconds.

\section{Characterization DSC}

Thermodynamic methods were implemented for evaluating the thermal stress of pure drug and the excipients as well as their interactions during the development of formulation. DSC analysis confirmed the thermal changes of the formulations. Rosuvastatin had two endothermic peaks at $79.2^{\circ} \mathrm{C}$ and 131.6, as demonstrated in Figure 6A. Thermogram of physical mixture (rosuvastatin + Capmul MCM EP + Tween $20+$ Transcutol P) showed a sharp endothermic peak at $131^{\circ} \mathrm{C}$ which confirms the transition of crystalline 

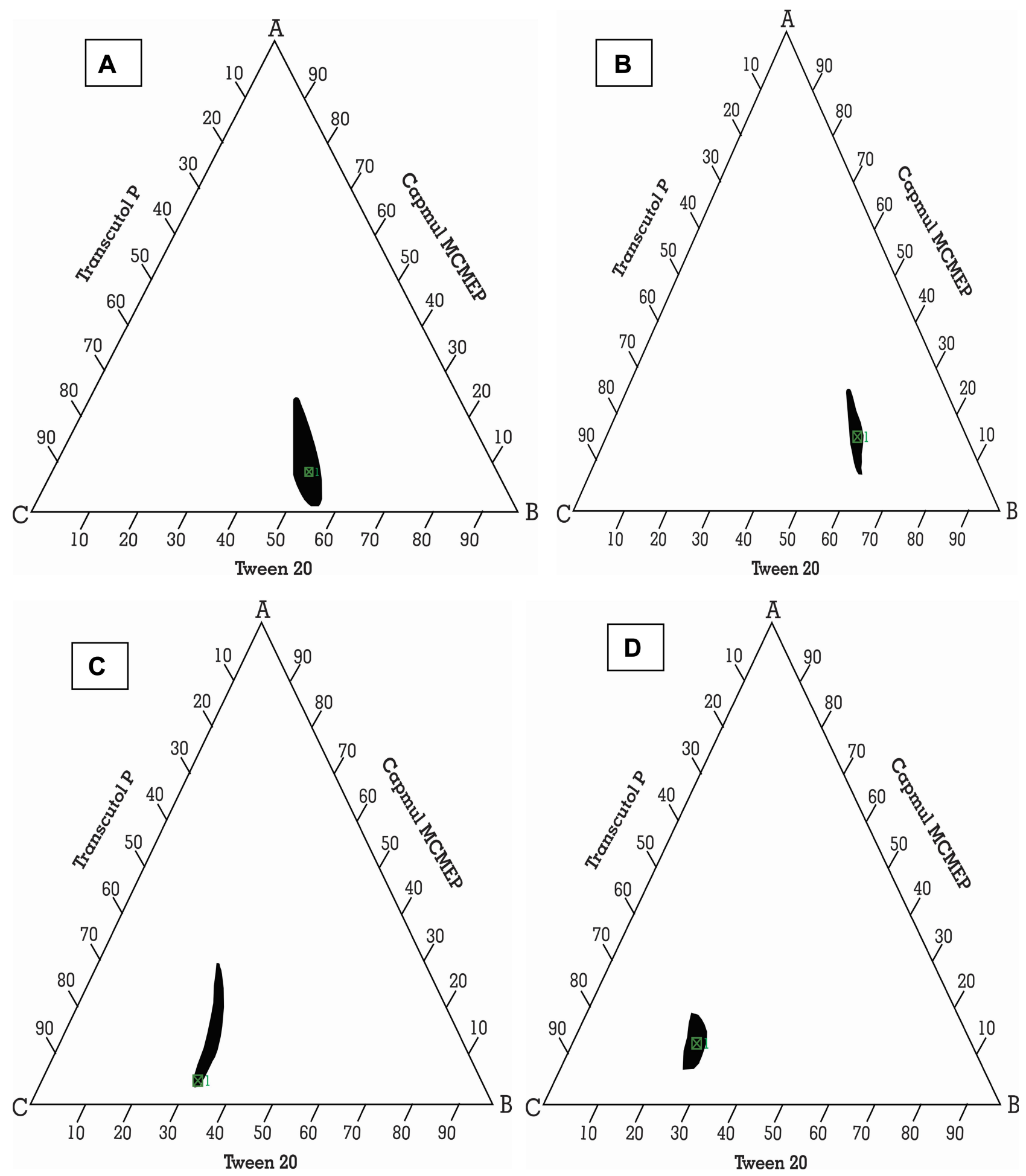

Figure 3 Ternary phase diagram of Capmul MCMEP, tween 20 and transcutol P at Smix ratios (A) I:I, (B) 2:I, (C) I:2, and (D) I:3. The colored region (black) represents nano-emulsion formation region.

to liquid crystal form (Figure 6B). This might be the melting of rosuvastatin crystalline form change. ${ }^{31}$ The peaks of rosuvastatin and excipients disappeared in the DSC curve of optimized SNEDDS formulation due to the amorphous state
(Figure 6C). These results indicated that rosuvastatin was completely dissolved in the blend of excipients and the interactions occurred among drug and excipients. The interactions between rosuvastatin and excipients contributed to 
Table 3 Composition of Various SNEDDS Formulations Suggested by Design Expert ${ }^{\circledR}$ and Their Responses

\begin{tabular}{|c|c|c|c|c|c|c|}
\hline \multirow{2}{*}{$\begin{array}{l}\text { Formulation } \\
\text { Code }\end{array}$} & \multicolumn{3}{|c|}{ Excipients Ratio } & \multirow{2}{*}{$\begin{array}{l}Y_{1} \\
(n m)\end{array}$} & \multirow{2}{*}{$\begin{array}{l}\mathbf{Y}_{2} \\
(\%)\end{array}$} & \multirow{2}{*}{$\begin{array}{l}\mathbf{Y}_{3} \\
\text { (sec) }\end{array}$} \\
\hline & $\begin{array}{l}X_{1} \\
(\%)\end{array}$ & $\begin{array}{l}X_{2} \\
(\%)\end{array}$ & $\begin{array}{l}X_{3} \\
(\%)\end{array}$ & & & \\
\hline $\mathrm{FI}$ & 0.05 & 0.4175 & 0.5325 & 17.89 & 98 & 16 \\
\hline F2 & 0.14 & 0.5 & 0.36 & 14.69 & 99.5 & 15 \\
\hline F3 & 0.3 & 0.24 & 0.46 & 130 & 91 & 38 \\
\hline $\mathrm{F} 4$ & 0.28 & 0.40 & 0.32 & 104.7 & 94.5 & 22 \\
\hline F5 & 0.3 & 0.5 & 0.2 & 114 & 97 & 30 \\
\hline F6 & 0.13 & 0.42 & 0.45 & 23.56 & 94.5 & 18 \\
\hline F7 & 0.21 & 0.49 & 0.30 & 43.41 & 96 & 21 \\
\hline F8 & 0.23 & 0.31 & 0.46 & 87.2 & 87 & 26 \\
\hline F9 & 0.13 & 0.42 & 0.45 & 24.24 & 95 & 18 \\
\hline FIO & 0.14 & 0.31 & 0.55 & 28.07 & 90 & 20 \\
\hline FII & 0.3 & 0.33 & 0.37 & 125.2 & 92 & 25 \\
\hline $\mathrm{FI} 2$ & 0.22 & 0.39 & 0.39 & 63.94 & 90 & 20 \\
\hline $\mathrm{FI3}$ & 0.06 & 0.5 & 0.44 & 15.89 & 99 & 14 \\
\hline $\mathrm{FI} 4$ & 0.25 & 0.2 & 0.55 & 132 & 86 & 40 \\
\hline
\end{tabular}

Notes: Independent variable: $X_{1}$ as oil percentage (Capmul MCM EP), $X_{2}$ as surfactant percentage (Tween 20), and $X_{3}$ as a co-surfactant percentage (Transcutol $P$ ). Dependent variables: globule size $\left(Y_{1}\right)$, \%CDR $\left(Y_{2}\right)$ and selfemulsification time $\left(\mathrm{Y}_{3}\right)$.

entrapment of the rosuvastatin into the drug-loading system and development of rosuvastatin-loaded SNEDDS formulation. $^{43}$

\section{FT-IR}

In FT-IR spectrum of the pure rosuvastatin, $3364.57 \mathrm{~cm}^{-1}$ was stretching vibration peak of aromatic $\mathrm{N}-\mathrm{H}$, $1174.19 \mathrm{~cm}^{-1}$ vibration peak of $\mathrm{S}=\mathrm{O}, 965.20 \mathrm{~cm}^{-1}$ peak of aromatic $\mathrm{C}-\mathrm{H}$ bending, $3392.14 \mathrm{~cm}^{-1}$ was stretching vibration peak of carboxylic $\mathrm{O}-\mathrm{H}$, and $1547.59 \mathrm{~cm}^{-1}$ was stretching vibration peak of $\mathrm{C}=\mathrm{C}$, as shown in Figure 7A.

FT-IR spectrum of the physical mixture of rosuvastatin and excipients was in accordance with SNEDDS (Figures 7B and C), which was almost the superposition of FT-IR spectra of rosuvastatin and ingredients.

The main absorption peaks of rosuvastatin were observed in physical mixture and optimized SNEDDS formulation. ${ }^{40}$ In contrast, if specific interactions took place between drug and excipients, new peaks or a shift of existing peaks would appear. The overall FT-IR results proved no chemical interaction between drug and its excipients. ${ }^{52}$

\section{$\%$ transmittance}

It was estimated to assess the stability of SNEDDS formulation. It also offers some prediction for other formulation parameters such as uniformity and size of the globules. It was found to be $99.9 \pm 0.4 \%$ at $242 \mathrm{~nm}$, which confirmed its transparency, reduced chances of drug precipitation, and improved solubilization limit subsequent to dispersion into buffering media. ${ }^{53}$

\section{Test for Robustness Dilution}

The creation of a homogeneous nano-emulsion from optimized SNEDDS is extremely important in different media since drug assimilation may be affected by in vivo precipitation. For this test, SNEDDS were dispersed in various media for simulating the in vivo milieu after 100 times dilution of this formulation. This formulation did not indicate drug precipitation, cloudiness or partition of phase even after 24 hours. This confirms that SNEDDS passed robustness dilution analysis. These results guaranteed the possibility of a consistent profile of drug release amid in vivo state.

\section{Measurement of Viscosity}

This parameter was evaluated with Brookfield hydromotion viscometer that resulted in $120 \pm 5 \mathrm{cps}$ for optimized SNEDDS. This test was performed in triplicate. These results assure that this SNEDDS can be easily transferred or filled into capsule shells for their stockpiling.

\section{Estimation of Cloud Point}

It aids in looking at the effect of temperature on phase behavior of SNEDDS, which is one of the major problems identified with nano-emulsion, especially while utilizing non-ionic surfactants.

It is defined as the temperature above which SNEDDS clarity transforms into cloudiness. A perfect formulation ought to stay as a single phase with a clear solution at its stockpiling temperature and the temperature of its proposed use. It was a lot higher $\left(65^{\circ} \mathrm{C}\right)$, demonstrating the stability of formulation at physiological temperature. At higher temperature, phase detachment can emerge on account of decreased solubility of surfactant in a fluid. It can decrease solubilization of drug and SNEDDS' dependability because the cloud point ought to be more than $37^{\circ} \mathrm{C}$. ${ }^{73}$

\section{Evaluation of Drug Content}

It was found to be $99.59 \pm 0.8 \%$ with UV spectrophotometer in optimized SNEDDS formulation that confirmed the dose accuracy of SNEDDS formulation.

\section{Droplet Size, PDI, and Zeta Potential}

Droplet size is one of the parameters that help in the evaluation of stability characteristics of nano-emulsion of SNEDDS. That results in enhanced retention of the drug 


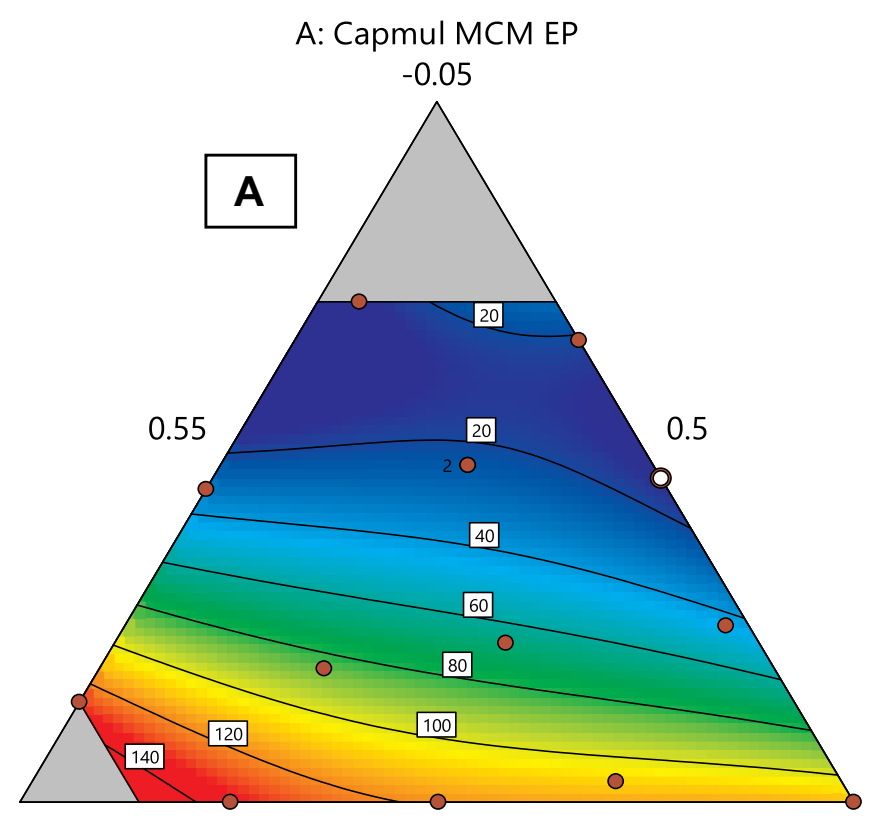

0.15

B: Tween 20
0.3

Globule size (nm)

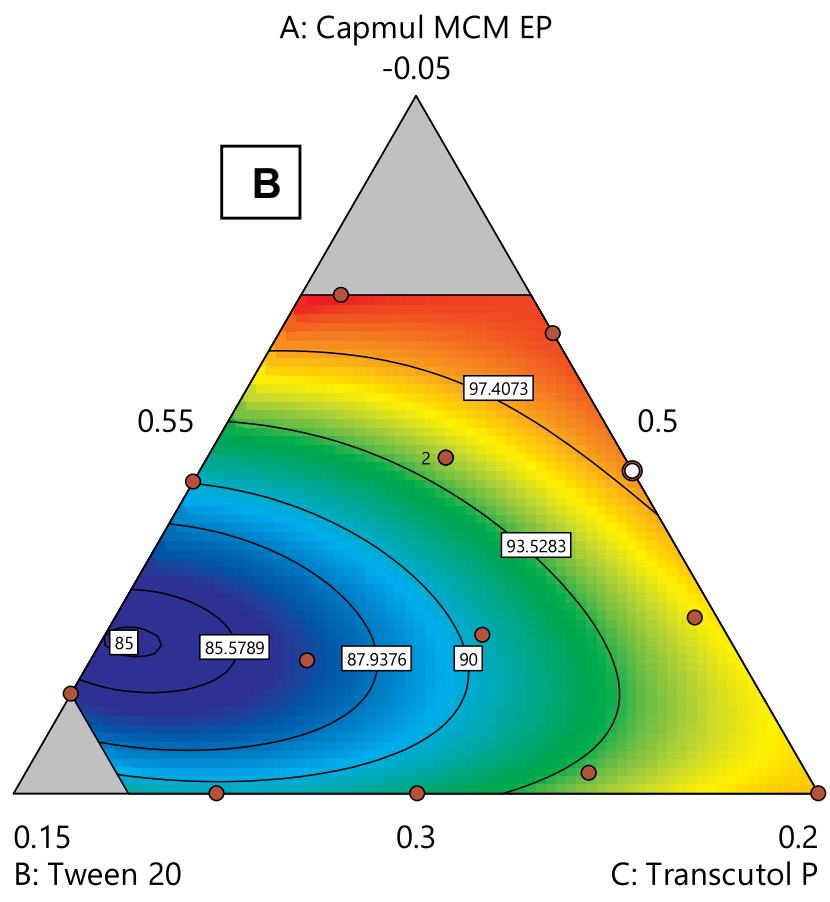

$\% \operatorname{CDR}(\%)$

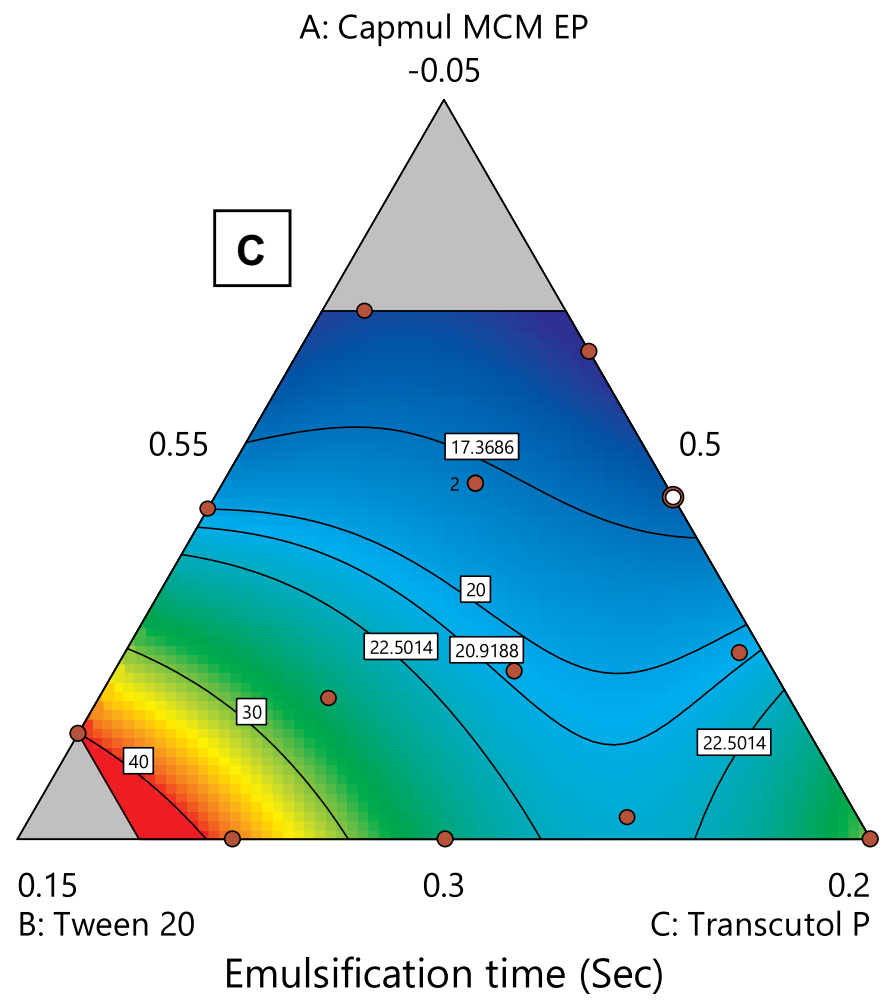

Figure 4 Various 2-D counter plots for response: (A) globule size, (B) \% CDR, and (C) self-emulsification time.

and its better oral bioavailability. Its nano range size confirms larger interfacial surface zone for the absorption of the drug and upgraded bioavailability. Henceforth, its nano range may enable the efficient release of the drug. The droplet size of SNEDDS indicates that globules of the emulsion have nanometric range $(14.69 \mathrm{~nm})$ with PDI 
Table 4 Results of ANOVA

\begin{tabular}{|l|l|l|l|l|l|l|}
\hline \multicolumn{2}{|l|}{ Results of ANOVA } \\
\hline Response & Sum of Squares & df & Mean Square & F-value & p-value & Model \\
\hline $\mathbf{Y}_{\mathbf{1}}$ & $29,020.80$ & 9 & 3224.53 & 89.87 & 0.0003 & Significant \\
$\mathbf{Y}_{\mathbf{2}}$ & 239.80 & 9 & 26.64 & $114.4 \mathrm{I}$ & 0.0002 & Significant \\
$\mathbf{Y}_{\mathbf{3}}$ & 841.79 & 9 & 93.53 & 328.64 & $<0.000$ I & Significant \\
\hline
\end{tabular}

under 0.5 , which demonstrates consistency in distribution of droplet size (Figure S3). ${ }^{74}$ The value of zeta potential was found to be $-4.09 \mathrm{mV}$. The obtained size of the
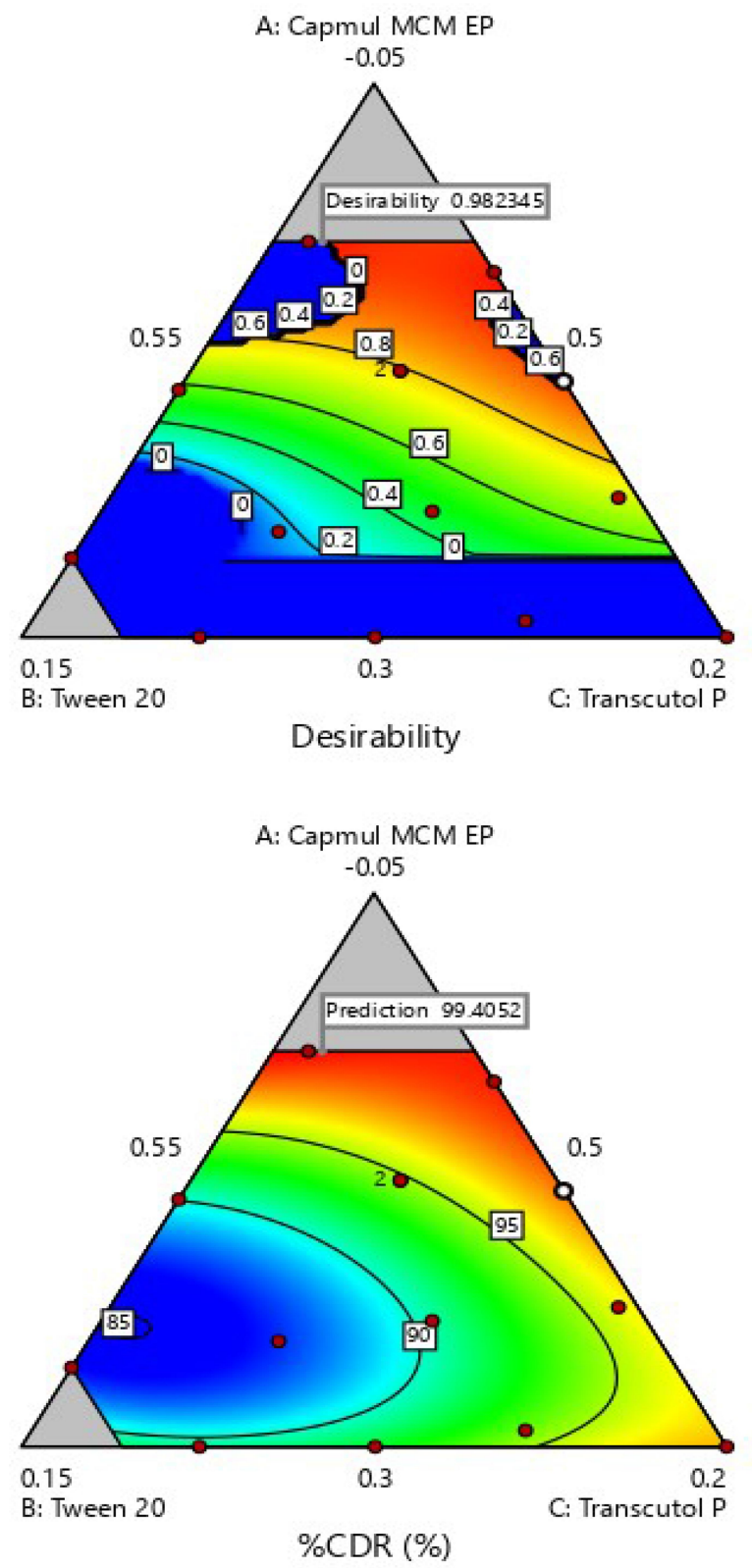

formulations seems to be too small that kidney is capable of rapidly removing molecules from the vascular compartment mostly as the injected forms and therefore, renal

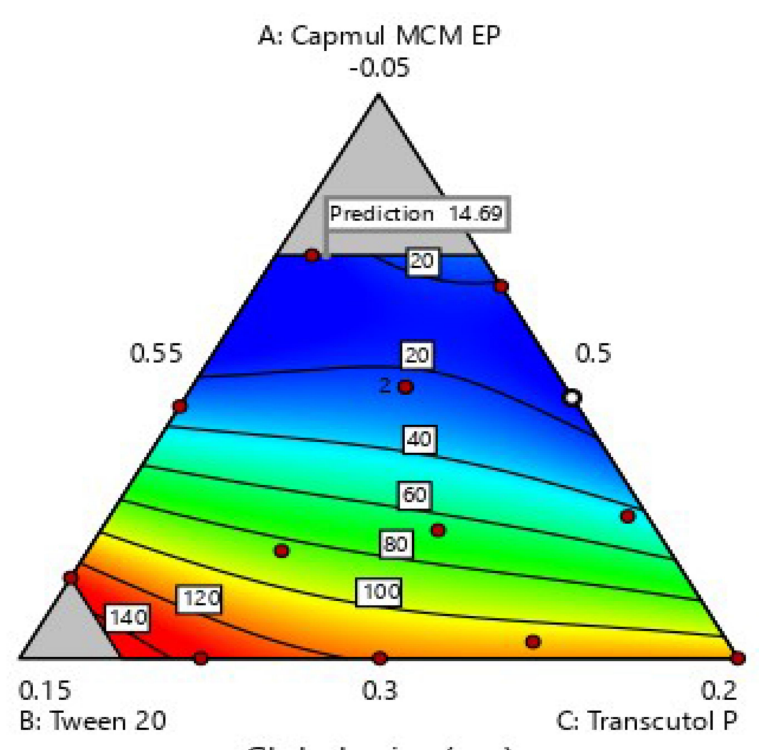

Globule size $(\mathrm{nm})$

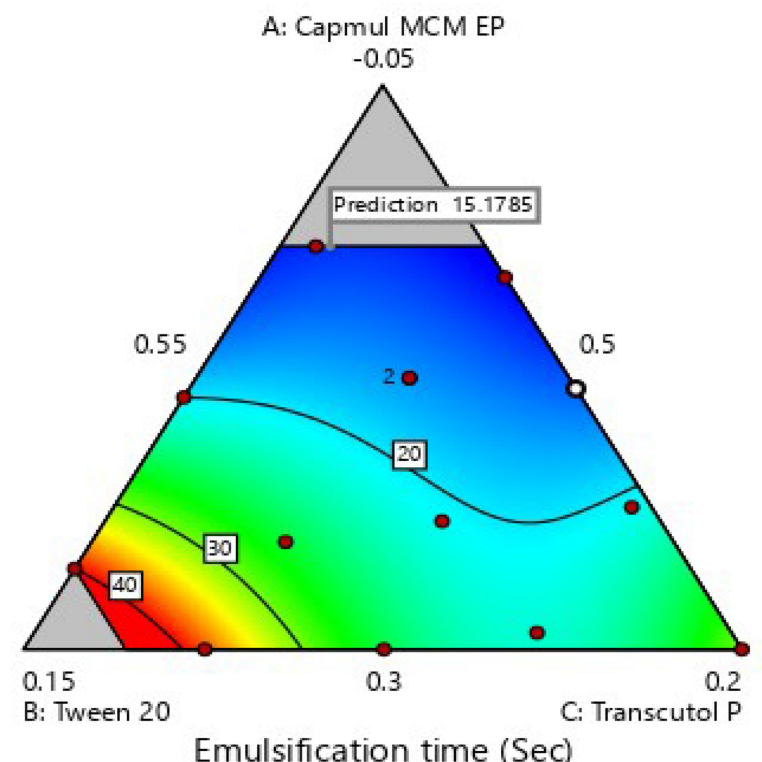

Figure 5 Desirability index for optimized rosuvastatin-loaded SNEDDS. 


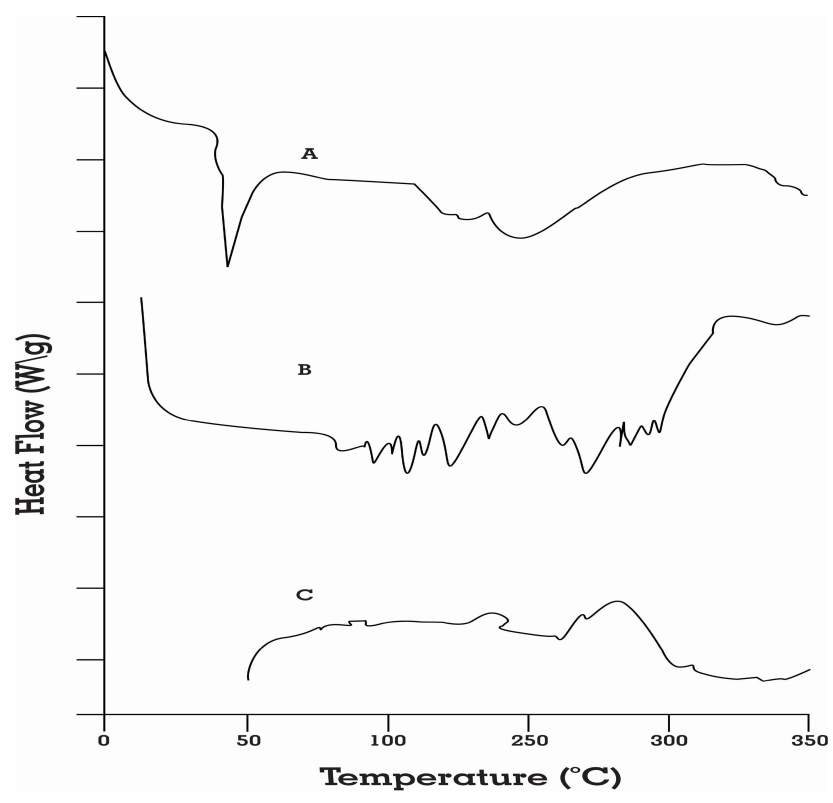

Figure 6 DSC spectra of (A) pure rosuvastatin, (B) physical mixture of drug and excipients, and $(\mathbf{C})$ optimized SNEDDS formulation.

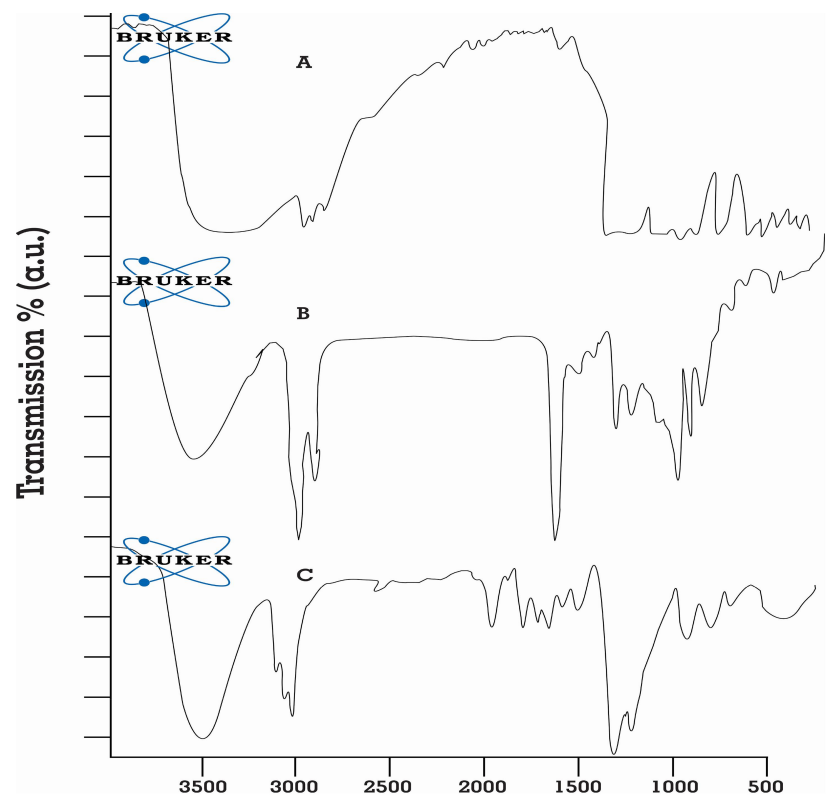

Figure 7 FT-IR spectrum of (A) pure rosuvastatin, (B) physical mixture of drug and excipients, and (C) optimized SNEDDS formulation.

excretion represents a desirable pathway for nanoemulsion removal with minimal catabolism or breakdown from the human body, to avoid the possible side effects. ${ }^{75}$

The stability of colloidal dispersion relies upon zeta potential value. For smaller droplets, its high value will confirm the stability of the formulation electrically since an increase in surface charge restricts the accumulation of droplets. At the point when potential is high, repulsion is more than attraction. This will result in a dispersed and deflocculated system which means the system will not break. In the current investigation, its value was reported to be negative because of the non-ionic surfactant that was present in the preparation. They make a negatively charged interface at neutral $\mathrm{pH}^{76,77}$

\section{Drug Entrapment Efficiency}

$\mathrm{EE}$ is a vital indicator for examining the drug loading capacity of nano-pharmaceutics; the larger the value the better the drug loading capacity. The EE of rosuvastatin in optimized SNEDDS formulation was found to be $99.52 \% \pm 0.86 \%$.

\section{Surface Morphology Examined via Transmission Electron Microscopy}

The microscopy of optimized SNEDDS formulation was examined using TEM micrographs. Transmission electron microscopy (TEM) revealed that optimized SNEDDS formulation exhibited a spherical shape structure with varying sizes of globules, as demonstrated in Figure 8. These results agreed with dynamic light scattering results, authenticating the achievability of SNEDDS formulation. The nanodroplets appeared dark, and the surroundings were found to be bright. Such findings prove the spontaneous formation of nanometer-range nanoemulsifying systems. ${ }^{78}$

\section{Dissolution (Multi-Media) Testing}

The results of solubility study demonstrated good solubility of rosuvastatin in selected media (Table S1). Three dissolution media were used for the dissolution profile of optimized SNEDDS whose outcomes are depicted in Figure 9. From the results, it was inferred that drug release was $>80 \%$ in a short time in all media. However, a gentle decline or change in drug discharge was reported at $\mathrm{pH} 1.2$ and 4.5. Overall SNEDDS formulation brought about amazingly enhanced drug discharge in multi-media dissolution testing. ${ }^{79}$ Drug release from SNEDDS was based on a simple diffusion process from a lipophilic liquid phase to an aqueous liquid phase. ${ }^{80}$

\section{Comparative Investigation of SNEDDS with Pure Drug and Marketed Tablets in Terms of Dissolution Profile}

This investigation was carried out with SNEDDS, marketed tablets, and pure drug. The reported results are summed up in Figure 10.

This investigation demonstrated that SNEDDS improved the dissolution rate of rosuvastatin up to 1.11 


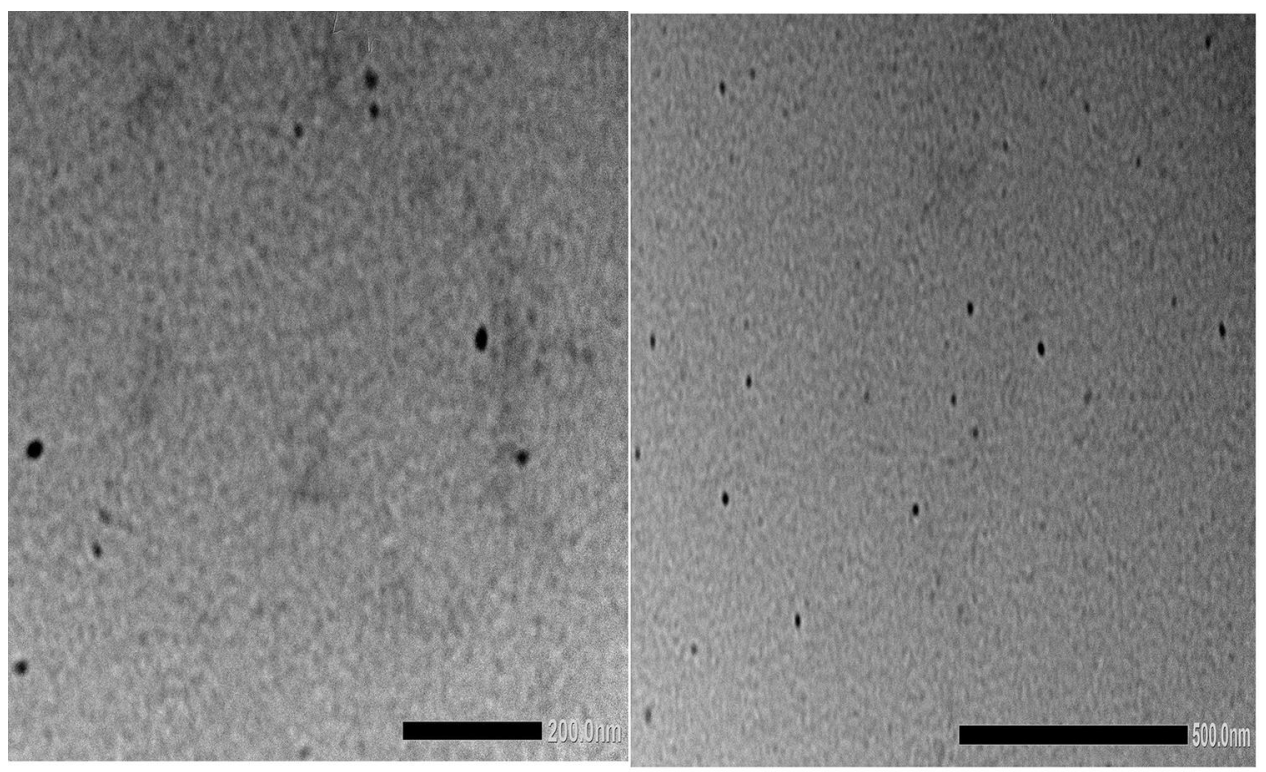

Figure 8 Transmission electron microscopy (TEM) of optimized SNEDDS formulation.

and 1.64 times compared to marketed tablets and pure drug respectively. These outcomes are identical or similar to results obtained by a number of other analysts/researchers. Alteration of the crystalline nature of the drug into an amorphous form is responsible for improved dissolution because this form is thermodynamically stable and SNEDDS offers conversion of solid-to-liquid phase easily. It is well recognized that the transformation of structure improves its disintegration pace to improve bioavailability. ${ }^{81}$ Another explanation is the presence of drug as a solubilized form inside nano-emulsion droplets and the suspending of drug in nanosized range in SNEDDS. All the results demonstrated quicker drug discharge than pure rosuvastatin in dissolution media.

\section{Dynamic in vitro Lipolysis Study for Investigation of Food Impact}

One of the most marvelous and insufficiently recognized capabilities of SNEDDS is that they "collaborate" with the content of GI that directly affects their potential. In the

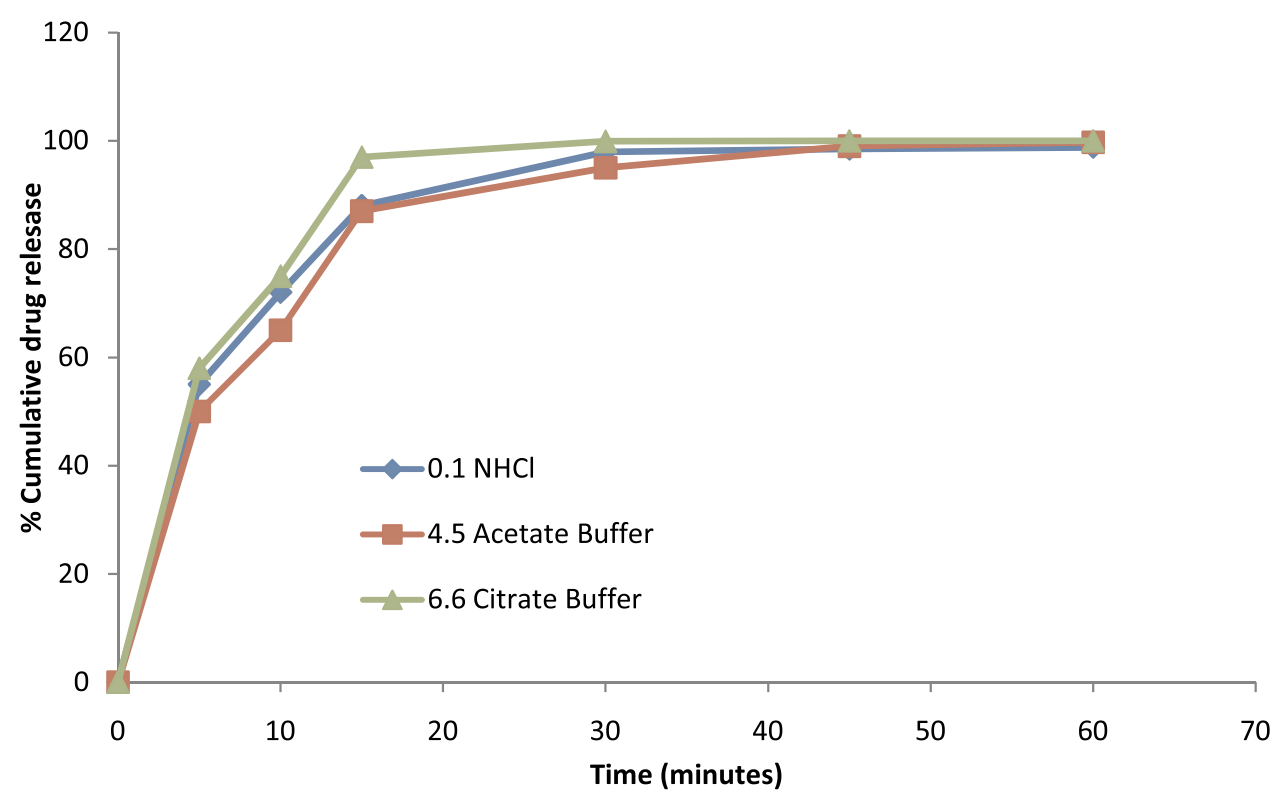

Figure 9 Dissolution (multi-media) testing of rosuvastatin SNEDDS. Each value represents the mean \pm SD $(n=3)$. 


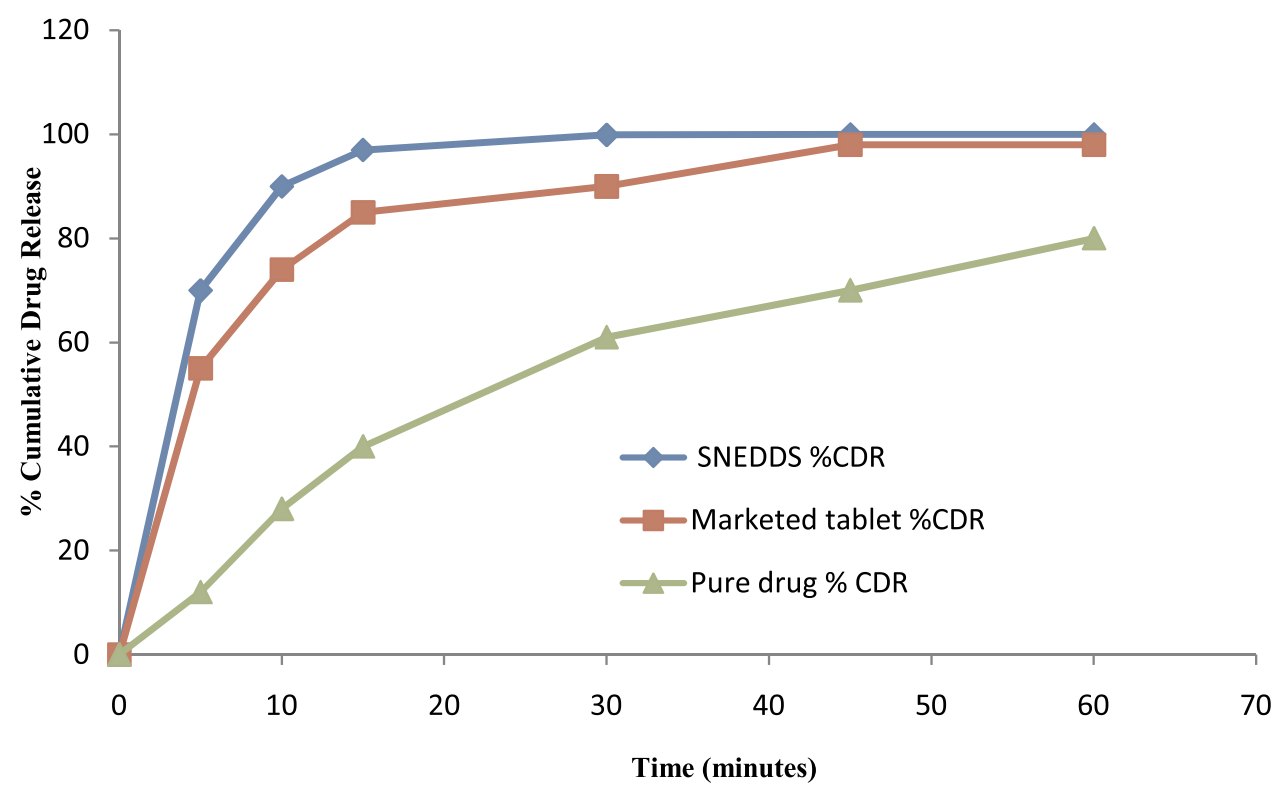

Figure 10 Comparative dissolution study ( $\mathrm{pH} 6.6$ citrate buffer) of rosuvastatin-loaded SNEDDS, pure drug and marketed tablet. Each value represents the mean \pm SD $(n=3)$.

small intestine (SI), digestion of dietary TG is commonly very rapid and a variety of non-ionic esters behave as a substrate of pancreatic lipase or other esterase. This procedure helps in scattering of the drug in the presence of BS/PLs from formulation and improves their assimilation. Thus, assessment of the digestion of lipids can be crucial since they speculate the possibility of formulation for precipitation of drug in SI.

Changing the limit of solubilization that emerged all through this procedure was of incredible importance to assess food impact by methods of in vitro lipolysis. ${ }^{62}$ During this study, it was very important to establish whether there was some possibility of precipitation of drug within 30 minutes. The fasted condition outcomes authenticated that rosuvastatin existed in the solubilized form in SNEDDS that resulted in about $98.32 \pm 0.05 \%$ drug discharge. Similar results were reported under fed condition $(98.52 \pm 0.05 \%)$ which indicates that SNEDDS formulation was capable of maintaining a solubilized form of rosuvastatin which is important for retention of the drug.

In this way, SNEDDS maintained a strategic distance from food impact in terms of drug release, which has been stated in various works of literature, and was found to be a correct hypothesis for SNEDDS. This proposes that SNEDDS conquered the impact of food on the release of drug. Along these lines, SNEDDS can improve patient compliance, particularly in patients who are not capable of consuming their drug with meals.

\section{Stability Study}

It was found that SNEDDS formulation was physically and chemically stable during six months of accelerated stability study at $40^{\circ} \mathrm{C} / 75 \% \mathrm{RH}$. Results of the stability study for rosuvastatin SNEDDS are summarized in Table 5.

From these data, it was concluded that there was no considerable difference in rosuvastatin SNEDDS after six months of the accelerated stability study. Hence, it was inferred that rosuvastatin SNEDDS passed stability study.

\section{Pharmacodynamic Studies}

This investigation was conducted with rosuvastatin SNEDDS (F-2), marketed tablets and pure drug. The total $\mathrm{CH}, \mathrm{TG}$, and HDL results for each group are summarized in Table 6 and Figure 11. This study demonstrated a considerable variation in the percentage of parameters of CTG, PTG (no drug), MTG (rosuvastatin tablet $20 \mathrm{mg}$ ), RTG (pure drug) and TT (SNEDDS) group ( $<<0.001)$.

After the administration of a diet with a high quantity of fat for 28 days, all the groups showed a significant elevation of lipid content in the serum which indicates a hyperlipidemic condition in rats. After treatment of TTG, this group's results showed remarkable variation in lipidic contents of the serum including $\mathrm{CH}, \mathrm{TG}, \mathrm{HDL}$, LDL and VLDL as compared to the PTG, MTG and RTG as delineated in Figure 11. All the groups showed initiation of their pharmacodynamic impacts in fluctuating 
Table 5 Stability Data of Optimized Rosuvastatin SNEDDS Formulation $(n=6)$

\begin{tabular}{|c|c|c|c|c|}
\hline $\begin{array}{l}\text { Test } \\
\text { Parameters }\end{array}$ & Initial & $40^{\circ} \mathrm{C} / 75 \% \mathrm{RH} / \mathrm{IM}$ & $40^{\circ} \mathrm{C} / 75 \% \mathrm{RH} / 3 \mathrm{M}$ & $40^{\circ} \mathrm{C} / 75 \% \mathrm{RH} / 6 \mathrm{M}$ \\
\hline Description & $\begin{array}{l}\text { Whitish colored capsules } \\
\text { containing clear liquid }\end{array}$ & $\begin{array}{l}\text { Whitish colored capsules } \\
\text { containing clear liquid }\end{array}$ & $\begin{array}{l}\text { Whitish colored capsules } \\
\text { containing clear liquid }\end{array}$ & $\begin{array}{l}\text { Whitish colored capsules } \\
\text { containing clear liquid }\end{array}$ \\
\hline$\%$ CDR & $98.9 \pm 1.2$ & $95.7 \pm 2.1$ & $96.9 \pm 0.7$ & $99.8 \pm 1.0$ \\
\hline $\begin{array}{l}\text { Disintegration } \\
\text { time }\end{array}$ & $5 \pm 0.5 \mathrm{~min}$ & $5 \pm 0.3 \mathrm{~min}$ & $6 \pm 1 \mathrm{~min}$ & $6 \pm 0.2 \mathrm{~min}$ \\
\hline
\end{tabular}

Notes: \%CDR-Percentage of cumulative drug release. Data are presented as the mean \pm SD.

Table 6 Lipid Profile in Experimental Animals with Mean \pm Std. Deviation $(n=6)$

\begin{tabular}{|c|c|c|c|c|c|c|}
\hline Parameters & 0 Day & Control & Placebo & SNEDDS & Marketed Tablet & Pure drug \\
\hline $\mathrm{CH}(\mu \mathrm{g} / \mathrm{d} \mathrm{l})$ & $70 \pm 1.8$ & $215.7 \pm 2.88$ & $205.3 \pm 2.58$ & $75.83 \pm 2.64 * * * \$ \wedge \wedge \wedge$ & $90.33 \pm 2.58 * * \wedge \wedge$ & $125.2 \pm 2.48$ \\
\hline HDL ( $\mu \mathrm{g} / \mathrm{dl})$ & $18.8 \pm 2.7$ & $20.67 \pm 1.37$ & $24.83 \pm 0.98$ & $46.50 \pm 1.87 * * * \$_{\wedge \wedge \wedge}$ & $40.00 \pm \mid .4 I^{* * \wedge \wedge}$ & $31.17 \pm 1.17^{*}$ \\
\hline LDL $(\mu \mathrm{g} / \mathrm{dl})$ & $30.7 \pm 2.7$ & $|5| .9 \pm 3.4$ & $122.6 \pm 2.12$ & $\mid 4.17 \pm 2.85^{* * * \$ \wedge \wedge \wedge}$ & $32.27 \pm 1.66 * * * \wedge \wedge$ & $68.97 \pm 1.86$ \\
\hline TG $(\mu g / d l)$ & $79.3 \pm 1.9$ & $220.3 \pm 3.14$ & $210.3 \pm 1.86$ & $89.50 \pm 1.87 * * * \$ \wedge \wedge \wedge$ & $120.0 \pm 2.10^{* * \wedge \wedge}$ & $169.5 \pm 1.87^{*}$ \\
\hline VLDL( $\mu \mathrm{g} / \mathrm{dl})$ & $13.9 \pm 2.5$ & $43.13 \pm 0.58$ & $36.87 \pm 0.52$ & $15.17 \pm 0.53^{* * * \$ \wedge \wedge \wedge}$ & $\mid 8.07 \pm 0.52 * * * \wedge \wedge$ & $25.03 \pm 0.50 *$ \\
\hline
\end{tabular}

Notes: Data are presented as the mean \pm SD. ${ }^{* * *} p<0.001$ (highly significant); ${ }^{*} p<0.01$ (significant); ${ }^{*}<<0.05$ (less significant) $\left({ }^{*} a s\right.$ compared to control). ${ }^{\$} p<0.01 ;\left({ }^{\$}\right.$ as compared to marketed tablet). ${ }^{\wedge \wedge} \mathrm{p}<0.00 \mathrm{I} ;{ }^{\wedge \wedge} \mathrm{p}<0.0 \mathrm{I}$; ( ${ }^{\wedge}$ as compared to pure drug). $\mathrm{p}<0.00 \mathrm{I}$ (highly significant); $\mathrm{p}<0.0 \mathrm{I}$ (significant); $\mathrm{p}<0.05$ (less significant).

Abbreviations: $\mathrm{CH}$, cholesterol; HDL, high-density lipoprotein; LDL, low-density lipoprotein; TG, triglyceride; VLDL, very low density lipoprotein.

lipid content level in the serum after 28 days of the treatment $(\mathrm{p}<0.001)$.

It was summed up that TTG decreased the $\mathrm{CH}$ content level in serum more significantly in contrast to PTG, MTG and RTG as compared to CTG. A similar pattern was obtained for TG, LDL and VLDL contents. The percent expansion in HDL content level in serum of TTG was significantly more than PTG $(\mathrm{p}<0.001)$, MTG $(\mathrm{p}<0.01)$ and RTG $(\mathrm{p}<0.05)$ as compared to CTG.

This study established that the drug was highly effective when it was developed as a formulation of SNEDDS. This confirms that they were able to improve the therapeutic

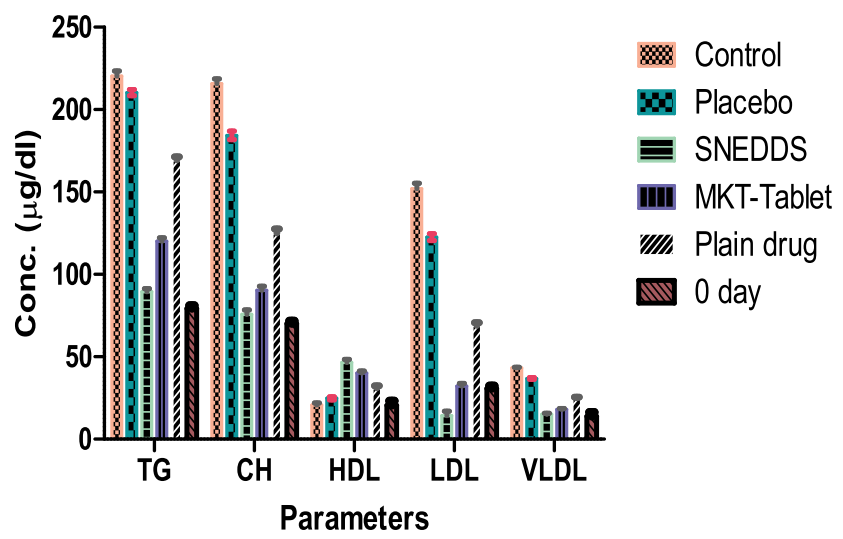

Figure I I Results of comparative lipid profile testing. Each value represents the mean $\pm S D(n=6)$. efficiency of rosuvastatin in contrast to the suspension of marketed tablets and pure drug. SNEDDS had a considerable impact on the lipid profile of rats after the experiment. Therefore, all these results confirmed that the tested formulation had superior in vivo potential compared to pure drug suspension in terms of pharmacodynamic response.

\section{Conclusion}

In this research, we developed SNEDDS with thermal stability in tropical conditions, capable of improving \% CDR and in vivo pharmacodynamic potential of rosuvastatin as compared to pure drug and marketed tablets. ${ }^{82}$ DoE methodology was employed for the development of SNEDDS by the selection of an optimum concentration of excipients. It was illustrated that this type of formulation had a rapid rate of dissolution in contrast to marketed tablets and pure drug because of nano-range of droplet size and negative charge of zeta potential for this formulation. This will result in an expansion of surface area for greater drug release. After in vitro lipolysis study, it was concluded that there was no significant variation in the concentration of solubilized rosuvastatin under fasted and fed state. All the physicochemical evaluations were conducted in biorelevant media to better predict in vivo behavior. From this, it can be concluded that SNEDDS are able to avoid food's effect in terms of drug release. SNEDDS also improved pharmacodynamics in the male rat 
compared to the suspension form of marketed tablets and pure drug. That is why SNEDDS was established: for the considerable improvement of bioavailability. This investigation involved the potential of SNEDDS for enhanced drug release profile, less food effect and better pharmacodynamics of the drug. All these outcomes suggest that SNEDSDS is an alternative approach for the delivery of rosuvastatin with superior bioavailability, patient compliance, and the least side effects.

\section{Abbreviations}

BCS, biopharmaceutical classification system; $\mathrm{CH}$, cholesterol; CTG, control treatment group; DoE, design of experiment; $\mathrm{Fa} / \mathrm{FeSSIF} \mathrm{V}-2$, fasted/fed state simulated intestinal fluid V-2; HDL, high-density lipoprotein; MTG, marketed treatment group; $\mathrm{NaCl}$, sodium chloride; $\mathrm{o} / \mathrm{w}$, oil in water; PDI, polydispersity index; PLs, phospholipids; PTG, placebo treatment group; RTG, reference treatment group; SI, small intestine; SNEDDS, selfnanoemulsifying drug delivery system; TG, triglyceride; TTG, test treatment group.

\section{Ethical Approval and Consent to Participate}

This investigation was approved by IAEC under registration no. 1767/RE/S/14/CPCSEA; vide reference no. 153 165 dated 14/12/2018.

\section{Acknowledgment}

The authors would like to extend their sincere appreciation to the Researchers Supporting Project number (RSP-2020/ 96), King Saud University, Riyadh, Saudi Arabia.

\section{Author Contributions}

All authors contributed to data analysis, drafting or revising the article, have agreed on the journal to which the article will be submitted, gave final approval of the version to be published, and agree to be accountable for all aspects of the work.

\section{Disclosure}

The authors declare that there is no conflict of interest.

\section{References}

1. Hwang Y-C. Response: comparison of the Efficacy of Rosuvastatin Monotherapy $20 \mathrm{mg}$ with Rosuvastatin $5 \mathrm{mg}$ and Ezetimibe $10 \mathrm{mg}$ Combination Therapy on Lipid Parameters in Patients with Type 2 Diabetes Mellitus (Diabetes Metab J 2019;43:582-9). Diabetes Metab J. 2019;43(6):915-916. doi:10.4093/dmj.2019.0213
2. Alshora DH, Ibrahim MA, Elzayat E, Almeanazel OT, Alanazi F, Mukherjee A. Rosuvastatin calcium nanoparticles: improving bioavailability by formulation and stabilization codesign. PLoS One. 2018;13(7):e0200218. doi:10.1371/journal.pone.0200218

3. Lee YJ, Cha SH, Kim H, Choi SE, Cho S, Park Y. Diallyl disulphide-loaded spherical gold nanoparticles and acorn-like silver nanoparticles synthesised using onion extract: catalytic activity and cytotoxicity. Artif Cells Nanomed Biotechnol. 2020;48(1):948-960. doi:10.1080/21691401.2020.1773485

4. Vashist A, Atluri V, Raymond A, et al. Development of multifunctional biopolymeric auto-fluorescent micro- and nanogels as a platform for biomedical applications. Front Bioeng Biotechnol. 2020;8:315. doi:10.3389/fbioe.2020.00315

5. Nair M, Jayant RD, Kaushik A, Sagar V. Getting into the brain: potential of nanotechnology in the management of NeuroAIDS. $A d v$ Drug Deliv Rev. 2016;103:202-217. doi:10.1016/j.addr.2016.02.008

6. Kaushik A, Jayant RD, Bhardwaj V, Nair M. Personalized nanomedicine for CNS diseases. Drug Discov Today. 2018;23(5):1007-1015. doi:10.1016/j.drudis.2017.11.010

7. Colone M, Calcabrini A, Stringaro A. Drug delivery systems of natural products in oncology. Molecules. 2020;25(19):E4560. doi:10.3390/molecules 25194560

8. Pal S, Nagy S, Bozo T, Kocsis B, Devay A. Technological and biopharmaceutical optimization of nystatin release from a multiparticulate based bioadhesive drug delivery system. Eur J Pharm Sci. 2013;49:258-264.

9. Vashist A, Kaushik A, Vashist A, et al. Nanogels as potential drug nanocarriers for CNS drug delivery. Drug Discov Today. 2018;23 (7):1436-1443. doi:10.1016/j.drudis.2018.05.018

10. Kaushik A, Jayant RD, Sagar V, Nair M. The potential of magneto-electric nanocarriers for drug delivery. Expert Opin Drug Deliv. 2014;11(10):1635-1646. doi:10.1517/17425247.2014.933803

11. Thomas N, Holm R, Garmer M, Karlsson JJ, Mullertz A, Rades T. Supersaturated self-nanoemulsifying drug delivery systems (Super-SNEDDS) enhance the bioavailability of the poorly water-soluble drug simvastatin in dogs. AAPS J. 2013;15:219-227.

12. Liu CS, Chen L, Hu YN, et al. Self-microemulsifying drug delivery system for improved oral delivery and hypnotic efficacy of ferulic acid. Int $J$ Nanomedicine. 2020;15:2059-2070. doi:10.2147/IJN. S240449

13. Gahlawat N, Verma R, Kaushik D. Recent developments in self-microemulsifying drug delivery system: an overview. Asian J Pharm. 2019;13(2):59-72.

14. Liu H, Mei J, Xu Y, et al. Improving The oral absorption of nintedanib by a self-microemulsion drug delivery system: preparation and in vitro/in vivo evaluation. Int J Nanomedicine. 2019;14:8739-8751. doi:10.2147/IJN.S224044

15. Suhair S, Al-Nimry A, Khouloud A, Bashar M. Solid self-nanoemulsifying drug delivery system filled in enteric coated hard gelatin capsules for enhancing solubility and stability of omeprazole hydrochloride. Pharm Dev Technol. 2020;25(5):588-600. doi:10.1080/10837450.2020.1721536

16. Zeng L, Zhang YL. Development, optimization and in vitro evaluation of norcantharidin loaded self-nanoemulsifying drug delivery systems (NCTD-SNEDDS). Dev Technol. 2016;22(3):1-35. doi:10.1080/10837450.2016.1219915

17. Kalantari A, Kósa D, Nemes D, Ujhelyi Z, Fehér F, Vecsernyés M. Self-nanoemulsifying drug delivery systems containing Plantago lanceolata-An assessment of their antioxidant and anti-inflammatory effects. Molecules. 2017;22(10):1773. doi:10.3390/molecules22101773

18. Alhasani KF, Kazi M, Ibrahim MA, Shahba AA, Alanazi FK. Selfnanoemulsifying ramipril tablets: A novel delivery system for the enhancement of drug dissolution and stability. Int J Nanomedicine. 2019;14:5435-5448. doi:10.2147/IJNS203311 
19. Patki M, Giusto K, Gorasiya S, Reznik SE, Patel K. 17- $\alpha$ hydroxyprogesterone nanoemulsifying preconcentrate-loaded vaginal tablet: A novel noninvasive approach for the prevention of preterm birth. Pharmaceutics. 2019;11(7):335. doi:10.3390/pharmaceutics11070335

20. Alskär LC, Keemink J, Johannesson J. Impact of drug physicochemical properties on lipolysis-triggered drug supersaturation and precipitation from lipid-based formulations. Mol Pharm. 2018;15 (10):4733-4744. doi:10.1021/acs.molpharmaceut.8b00699

21. Gupta A, Eral HB, Hatton TA, Doyle PS. Nanoemulsions: formation, properties and applications. Soft Matter. 2016;12(11):2826-2841. doi: $10.1039 / \mathrm{c} 5 \mathrm{sm} 02958 \mathrm{a}$

22. Solans C, Izquierdo P, Nolla J, Azemar N, Garcia-Celma MJ. Nanoemulsions. Curr Opinion in Colloid Interface Sci. 2005;10(3-4):102-110. doi:10.1016/j.cocis.2005.06.004

23. Bazylińska U, Saczko J. Nanoemulsion-templated polylelectrolyte multifunctional nanocapsules for DNA entrapment and bioimaging. Colloids Surf B Biointerfaces. 2016;137:191-202. doi:10.1016/j. colsurfb.2015.07.056

24. Heshmati N, Cheng X, Eisenbrand G, Fricker G. Enhancement of oral bioavailability of E804 by self-nanoemulsifying drug delivery system (SNEDDS) in rats. J Pharm Sci. 2013;102:3792-3799.

25. Gué E, Since M, Ropars S, Herbinet R, Pluart L, Malzert-Fréon A. Evaluation of the versatile character of a nanoemulsion formulation. Int J Pharm. 2016;498(1-2):49-65.

26. Gamal W, Fahmy RH, Mohamed MI. Development of novel amisulpride-loaded liquid self-nanoemulsifying drug delivery systems via dual tackling of its solubility and intestinal permeability. Drug Dev Ind Pharm. 2017;43(9):1530-1548.

27. ElShagea HN, ElKasabgy NA, Fahmy RH, Basalious EB. Freezedried self nanoemulsifying self-nanosuspension (SNESNS): A new approach for the preparation of a highly drug-loaded dosage form. AAPS PharmSciTech. 2019;20:258. doi:10.1208/ s12249-019-1472-2

28. Bharti D, Pandey P, Verma R, Kaushik D. Development and characterization of rosuvastatin loaded self-emulsifying drug delivery system. Appl Clinical Res Clinical Trials Reg Affairs. 2018;5:1-8.

29. Verma R, Mittal V, Kaushik D. Quality based design approach for improving oral bioavailability of valsartan loaded SMEDDS and study of impact of lipolysis on the drug diffusion. Drug Deliv Letters. 2018;8(2):130-139.

30. Lee JH, Kim HY, Cho YH, Koo TS, Lee GW. Development and evaluation of raloxifene-hydrochloride-loaded supersaturatable SMEDDS containing an acidifier. Pharmaceutics. 2018;10(78):1-12.

31. Panigrahi KC, Patra N, Rao MEB. Quality by design enabled development of oral self-nanoemulsifying drug delivery system of a novel calcimimetic cinacalcet $\mathrm{HCl}$ using a porous carrier: in vitro and in vivo characterization. AAPS PharmSciTech. 2019;20:216. doi:10.1208/s12249-019-1411-2

32. Johnson B, Nornoo AO, Zheng H, Lopes LB, Johnson-Restrepo B, Kannan K. Oral microemulsions of paclitaxel: in situ and pharmacokinetic studies. Eur J Pharm Biopharm. 2008;71(2):310-317.

33. Patel MH, Mundada VP, Sawant KK. Novel drug delivery approach via self-microemulsifying drug delivery system for enhancing oral bioavailability of asenapine maleate: optimization, characterization, cell uptake, and in vivo pharmacokinetic studies. AAPS PharmSciTech. 2019;20(44):1-8. doi:10.1208/s12249-0181212-z

34. Kim RM, Jang DJ, Kim YC, Yoon JH, Min KA. Flurbiprofen-loaded solid SNEDDS preconcentrate for the enhanced solubility, in vitro dissolution and bioavailability in rats. Pharmaceutics. 2018;10 (4):247. doi:10.3390/pharmaceutics 10040247

35. Son HY, Chae BR, Choi JY, Shin DJ, Goo YT, Lee ES. Optimization of self-microemulsifying drug delivery system for phospholipid complex of telmisartan using D-optimal mixture design. PLoS One. 2018;13(12):1-17. doi:10.1371/journal.pone.0208339
36. Mura P, Furlanetto S, Cirri M, Maestrelli F, Marras AM, Pinzauti S. Optimization of glibenclamide tablet composition through the combined use of differential scanning calorimetry and D-optimal mixture experimental design. J Pharm Biomed Anal. 2005;37(1):65-71. doi:10.1016/j.jpba.2004.09.047

37. Hosny KM, Aldawsari HM, Bahmdan RH, et al. Preparation, optimization, and evaluation of hyaluronic acid-based hydrogel loaded with miconazole self-nanoemulsion for the treatment of oral thrush. AAPS PharmSciTech. 2019;20(297):1-12. doi:10.1208/s12249-019-1496-7

38. Eleftheriadis GK, Mantelou P, Karavasili C, Chatzopoulou P, Katsantonis D, Irakli M. Development and characterization of a self-nanoemulsifying drug delivery system comprised of rice bran oil for poorly soluble drugs. AAPS PharmSciTech. 2019;20:78. doi:10.1208/s12249-018-1274-y

39. Usfda. Available from: https://www.accessdata.fda.gov/scripts/cder/ dissolution/dsp_Search\%20Results.cfm. Accessed January 08, 2021.

40. Rangaraj N, Shah S, Maruthi AJ, et al. Quality by design approach for the development of self-emulsifying systems for oral delivery of febuxostat: pharmacokinetic and pharmacodynamic evaluation. AAPS PharmSciTech. 2019;20:267. doi:10.1208/s12249-019-1476-y

41. Rani R, Dahiya S, Dhingra D, et al. Antidiabetic activity enhancement in streptozotocin + nicotinamide-induced diabetic rats through combinational polymeric nanoformulation. Int $J$ Nanomedicine. 2019;14:4383-4395. doi:10.2147/IJN.S205319

42. Alshehri S, Imam SS, Hussain A, et al. Flufenamic acid-loaded self-nanoemulsifying drug delivery system for oral delivery: from formulation statistical optimization to preclinical anti-inflammatory assessment. J Oleo Sci. 2020;69(10):1257-1271. doi:10.5650/jos. ess 20070

43. Zhang J, Wen X, Dai Y, Xia Y. Mechanistic studies on the absorption enhancement of a self-nanoemulsifying drug delivery system loaded with norisoboldine-phospholipid complex. Int $J$ Nanomedicine. 2019;14:7095-7106.

44. Ahsan MN, Verma PR. Solidified self nano-emulsifying drug delivery system of rosuvastatin calcium to treat diet-induced hyperlipidemia in rat: in vitro and in vivo evaluations. Ther Deliv. 2017;8(3):125-136. doi:10.4155/tde-2016-0071

45. Liao H, Gao Y, Lian C, et al. Oral absorption and lymphatic transport of baicalein following drug-phospholipid complex incorporation in self-microemulsifying drug delivery systems. Int $J$ Nanomedicine. 2019;14:7291-7306. doi:10.2147/IJN.S214883

46. Wu L, Qiao Y, Wang L, Guo J, Wang G, He W. A self-microemulsifying drug delivery system (SMEDDS) for a novel medicative compound against depression: a preparation and bioavailability study in rats. AAPS PharmSciTech. 2015;16(5):1051-1058. doi:10.1208/s12249-014-0280-y

47. Shoshtari S, Wen J, Alany RG. Formulation and physicochemical characterization of imwitor 308 based self microemulsifying drug delivery systems. Chem Pharm Bull. 2010;58:1332-1338.

48. Agrawal AG, Kumar A, Gide PS. Formulation of solid self-nanoemulsifying drug delivery systems using N-methyl pyrrolidone as cosolvent. Drug Dev Ind Pharm. 2015;41:594-604.

49. Baloch J, Sohail MF, Sarwar HS, Kiani MH, Khan GM, Jahan S. Selfnanoemulsifying drug delivery system (SNEDDS) for improved oral bioavailability of chlorpromazine: in vitro and in vivo evaluation. Medicina. 2019;55(5):210. doi:10.3390/medicina55050210

50. Bang SP, Yeon CY, Adhikari N, Neupane S, Kim H, Lee DC. Cyclosporine A eyedrops with self-nanoemulsifying drug delivery systems have improved physicochemical properties and efficacy against dry eye disease in a murine dry eye model. PLoS One. 2019;14(11):e0224805. doi:10.1371/journal.pone.0224805

51. Pandey P, Ghimire G, Garcia J, et al. Single-entity approach to investigate surface charge enhancement in magnetoelectric nanoparticles induced by AC magnetic field stimulation. ACS Sens. 2020. doi:10.1021/acssensors.0c00664 
52. Ke Z, Hou X, Jia XB. Design and optimization of self-nanoemulsifying drug delivery systems for improved bioavailability of cyclovirobuxine D. Drug Des Devel Ther. 2016;10:2049-2060. doi:10.2147/DDDT.S106356

53. Alwadei M, Kazi M, Alanazi FK. Novel oral dosage regimen based on self-nanoemulsifying drug delivery systems for codelivery of phytochemicals - curcumin and thymoquinone. Saudi Pharm J. 2019;27:866-876.

54. Enin HA. Self-nanoemulsifying drug-delivery system for improved oral bioavailability of rosuvastatin using natural oil antihyperlipdemic. Drug Dev Ind Pharm. 2015;41(7):1047-1056. doi:10.3109/03639045.2014.983113

55. Jakab G, Fülöp V, Bozó T, Balogh E, Kellermayer N, Antal I. Optimization of quality attributes and atomic force microscopy imaging of reconstituted nanodroplets in baicalin loaded self-nanoemulsifying formulations. Pharmaceutics. 2018;10(4):275. doi:10.3390/pharmaceutics

56. Mohsin K. Design of lipid-based formulations for oral administration of poorly water-soluble drug fenofibrate: effects of digestion. AAPS PharmSciTech. 2012;13:637-646. doi:10.1208/s12249-0129787-2

57. Verma R, Kaushik D. Design and optimization of candesartan loaded self-nanoemulsifying drug delivery system for improving its dissolution rate and pharmacodynamic potential. Drug Deliv. 2020;1:756-771. doi:10.1080/10717544.2020.1760961

58. Mosgaard MD, Sassene P, Rades T, Müllertz A. Development of a high-throughput in vitro lipolysis model for rapid screening lipid-based drug delivery systems. Eur $J$ Pharm Biopharm. 2015;94:493-500.

59. Xiao L, Yi T, Liu Y, Zhou Z. The in vitro lipolysis of lipid-based drug delivery systems: A newly identified relationship between drug release and liquid crystalline phase. Bio Med Res Int. 2016;4:1-7.

60. Sassene P, Karen K, Williams HD, Mullertz A. Toward establishment of standardized in vitro tests for LbDDSs, Part 6: effect of varying pancreatin and calcium levels. Am Assoc Pharma Soci J. 2014;16 (6):1344-1357.

61. Williams HD, Anby MU, Sassene P, Kleberg K, Mullertz A, Porter JH. Toward the establishment of standardized in vitro tests for lipid-based formulations, Part 2. The effect of bile salt concentration and drug loading on the performance of type I, II, IIIA, IIIB, and IV formulations during in vitro digestion. Mol Pharm. 2012;101 (9):3286-3300.

62. Alshamsan A, Kazi M, Badran MM, Alanazi FK. Role of alternative lipid excipients in the design of self-nanoemulsifying formulations for fenofibrate: characterization, in vitro dispersion, digestion and ex vivo gut permeation studies. Front Pharmacol. 2018;9:1219. doi:10.3389/fphar.2018.01219

63. Izham MHM, Hussin Y, Aziz MNM, Yeap SK, Rahman HS, Masarudin MJ. Preparation and characterization of self nano-emulsifying drug delivery system loaded with citral and its antiproliferative effect on colorectal cells in vitro. Nanomaterials. 2019;9(1028):1-18. doi:10.3390/nano9071028

64. Kumar A, Nanda A. Design and optimization of simvastatin self-microemulsifying drug delivery system for enhanced therapeutic potential. Asian J Pharm. 2018;12(1):S159-S165.

65. Borhade V, Nair H, Hegde D. Design and evaluation of self-microemulsifying drug delivery system (SMEDDS) of tacrolimus. AAPS Pharm Sci Tech. 2008;9:13-21.

66. Parmar N, Singla N, Amin S, Kohli K. Study of cosurfactant effect on nanoemulsifying area and development of lercanidipine loaded (SNEDDS) self-nanoemulsifying drug delivery system. Colloids Surf B: Biointerfaces. 2011;86:327-338.
67. Qi X, Wang L, Zhu J, Hu Z, Zhang J. Self-double-emulsifying drug delivery system (SDEDDS): A new way for oral delivery of drugs with high solubility and low permeability. Int $J$ Pharm. 2011;409:245-251.

68. Nepal PR, Han HK, Choi HK. Preparation and in vitro-in vivo evaluation of Witepsol $\mathrm{H} 35$ based self-nanoemulsifying drug delivery systems (SNEDDS) of coenzyme Q (10). Eur J Pharm Sci. 2010;39:224-232.

69. Zhao Y, Wang C, Chow AH, Ren K, Gong T, Zhang Z. Selfnanoemulsifying drug delivery system (SNEDDS) for oral delivery of zedoary essential oil: formulation and bioavailability studies. Int J Pharm. 2010;383:170-177.

70. Balakumar K, Raghavan CV, Selvan NT, Prasad RH, Abdu S. Self-nanoemulsifying drug delivery system (SNEDDS) of rosuvastatin calcium: design, formulation, bioavailability and pharmacokinetic evaluation. Colloids Surf B: Biointerfaces. 2013;112:337-343.

71. Eltobshi AA, Mohamed EA, Abdelghani GM, Nouh AT. Selfnanoemulsifying drug-delivery systems for potentiated anti-inflammatory activity of diacerein. Int $J$ Nanomedicine. 2018;13:6585-6602. doi:10.2147/IJN.S178819

72. Chaudhri N. Formulation of amisulpride loaded nanoemulsion drug delivery system for the treatment of Schizophrenia. J Biomed Pharm Res. 2015;4(6):1-10.

73. Choi KO, Aditya NP, Ko S. Effect of aqueous pH and electrolyte concentration on structure, stability and flow behavior of non-ionic surfactant based solid lipid nanoparticles. Food Chem. 2014;147:239-244.

74. Shakeel F, Haq N, Elbadry M, Alanazi FK, Alsarra IA. Ultra fine super self-nanoemulsifying drug delivery system (SNEDDS) enhanced solubility and dissolution of indomethacin. $J$ Mol Liq. 2013;180:89-94.

75. Longmire M, Choyke PL, Kobayashi H. Clearance properties of nano-sized particles and molecules as imaging agents: considerations and caveats. Nanomedicine. 2008;3(5):703-717. doi:10.2217/ 17435889.3.5.703

76. Liu Y, Sun C, Hao Y, Jiang T, Zheng L, Wang S. Mechanism of dissolution enhancement and bioavailability of poorly water soluble celecoxib by preparing stable amorphous nanoparticles. J Pharm Pharm Sci. 2010;13(4):589-606. doi:10.18433/J3530J

77. Zhang Y, Zhi Z, Jiang T, Zhang J, Wang Z, Wang S. Spherical mesoporous silica nanoparticles for loading and release of the poorly water-soluble drug telmisartan. J Contr Release. 2010;145(3):257-263.

78. Bello V, Mattei G, Mazzoldi P, et al. Transmission electron microscopy of lipid vesicles for drug delivery: comparison between positive and negative staining. Microsc Microanal. 2010;16(4):456-461. doi:10.1017/S1431927610093645

79. Verma R, Kaushik D. Development, optimization, characterization and impact of in vitro lipolysis on drug release of telmisartan loaded SMEDDS. Drug Deliv Letters. 2019;9(9):330-340. doi:10.2174/ 2210303109666190614120556

80. Bernkop-Schnürch A, Jalil A. Do drug release studies from SEDDS make any sense? J Control Release. 2018;271:55-59. doi:10.1016/j. jconrel.2017.12.027

81. Kassem AA, Mohsen AM, Ahmed RS, Essam TM. Self-nanoemulsifying drug delivery system (SNEDDS) with enhanced solubilization of nystatin for treatment of oral candidiasis: design, optimization, in vitro and in vivo evaluation. J Mol Liquids. 2016;218(2):219-232.

82. Lindsay S, Dolores S, Marion M, Francisco BF, Auxiliadora D, Aikaterini L. Orally bioavailable and effective buparvaquone lipid based nanomedicines for visceral leishmaniasis. Mol Pharmaceutics. 2018;15:2570-2583. doi:10.1021/acs.molpharmaceut.8b00097 


\section{Publish your work in this journal}

The International Journal of Nanomedicine is an international, peerreviewed journal focusing on the application of nanotechnology in diagnostics, therapeutics, and drug delivery systems throughout the biomedical field. This journal is indexed on PubMed Central, MedLine, CAS, SciSearch ${ }^{\mathbb{R}}$, Current Contents ${ }^{\mathbb{B}} /$ Clinical Medicine,
Journal Citation Reports/Science Edition, EMBase, Scopus and the Elsevier Bibliographic databases. The manuscript management system is completely online and includes a very quick and fair peer-review system, which is all easy to use. Visit http://www.dovepress.com/ testimonials.php to read real quotes from published authors. 